\title{
Metformin Reduces Repeat Mild Concussive Injury Pathophysiology
}

\author{
Erica L. Underwood," JJohn B. Redell," Mark E. Maynard, Nobuhide Kobori, @Michael J. Hylin, \\ Kimberly N. Hood, Rebecca K. West, Jing Zhao, Anthony N. Moore, and Pramod K. Dash
}

https://doi.org/10.1523/ENEURO.0421-21.2021

Department of Neurobiology and Anatomy, The University of Texas McGovern Medical School, Houston, TX 77030

\begin{abstract}
Mild traumatic brain injury (mTBI) can initiate complex pathophysiological changes in the brain. Numerous cellular and molecular mechanisms underlying these pathologic changes are altered after injury, including those involved in energy utilization, excitotoxicity, ionic disturbances, and inflammation. It is thought that targeting multiple mechanisms may be necessary to produce meaningful reductions in brain pathology and to improve outcome. Previous studies have reported that the anti-diabetic drug metformin can also affect inflammatory, cell survival, and metabolic outcomes, possibly by acting on multiple targets and/or pathways. We therefore questioned whether metformin treatment can reduce pathology after repeat mild closed head injury $(\mathrm{rmCHI})$ in male C57BI/6 mice. We found that metformin, administered acutely after each head impact, resulted in markedly reduced white matter damage, astrogliosis, loss of hippocampal parvalbumin neurons, and improved mitochondrial function. In addition, both motor and cognitive functions were significantly improved when tested after discontinuation of the treatment. These studies suggest that metformin may be beneficial as a treatment for repeat concussion.
\end{abstract}

Key words: axonal injury; cognitive dysfunction; mild traumatic brain injury; oxygen consumption rate; repeat concussion; tissue respiration

\section{Significance Statement}

Repeat concussions (or repeat mild traumatic brain injury; rmTBI) can occur in persons participating in contact sports, and in military personnel. Unfortunately, there are no approved treatments to lessen the consequences of rmTBI. It is thought that outcome from rmTBI is influenced by several secondary events, including altered brain metabolism, inflammation, and damage to brain cells. Here, we show that the anti-diabetes drug metformin reduces repeat concussion brain pathology and improves motor and cognitive functions.

\section{Introduction}

Both clinical and experimental studies have shown that mild traumatic brain injury (mTBl; often referred to as concussion) can cause cognitive (e.g., learning and memory) and behavioral (e.g., anxiety and depression) impairments in the absence of overt brain damage (Jenkins et al., 1989; Lyeth et al., 1990; Gurkoff et al., 2006; Choe et al., 2012; Shenton et al., 2012; Barkhoudarian et al., 2016; Meconi et al., 2018). In the majority of cases, the cognitive and behavioral impairments do not persist, and resolve within days to weeks after a single concussive event

Received October 6, 2021; accepted November 9, 2021; First published December 13, 2021.

The authors declare no competing financial interests.
(Capruso and Levin, 1992; McCauley et al., 2014). In contrast, persons who sustain repeated $\mathrm{mTBI}(\mathrm{rmTBI})$ often present with prolonged cognitive and behavioral symptoms that, in some cases, can last months-to-years after injury. Although the cellular and molecular mechanisms that underlie these symptoms are still incompletely understood, it is thought that multiple mechanisms, including white matter damage, astrogliosis, neuroinflammation, and mitochondria dysfunction, are involved. There is a growing consensus that interventions that target multiple

Author contributions: E.L.U., J.B.R., A.N.M., and P.K.D. designed research; E.L.U., J.B.R., M.E.M., N.K., M.J.H., K.N.H., J.Z., and A.N.M. performed research; E.L.U., J.B.R., M.E.M., N.K., M.J.H., K.N.H., A.N.M., and P.K.D. analyzed data; E.L.U., J.B.R., R.K.W., A.N.M., and P.K.D. wrote the paper. 
pathologic mechanisms may be necessary to provide a meaningful improvement in patient outcomes (Saatman et al., 2008; Margulies et al., 2016).

Metformin (1,1-dimethylbiguanide hydrochloride) is a widely prescribed medication for type 2 diabetes. Although its mechanism(s) of action is not fully understood, current evidence suggests that metformin may target multiple signaling pathways to exert the numerous beneficial effects that have been reported in a variety of model systems (Viollet et al., 2012; Alimoradi et al., 2021; Kaneto et al., 2021). Some of the signaling pathways affected by metformin have implications for mitigating brain injury pathophysiology. For example, metformin can regulate cellular energy metabolism by activating AMP-activated protein kinase (AMPK), an important intracellular energy sensor that is deactivated following TBI (Hill et al., 2016). Metformin can also influence cellular energy balance and metabolism independently of the AMPK pathway by regulating mTOR (Kalender et al., 2010; Ben Sahra et al., 2011; Do et al., 2013). Inhibition of the expression and activation of the proinflammatory transcription factor nuclear factor $\kappa \mathrm{B}(\mathrm{NF}-\kappa \mathrm{B})$ may contribute to the many anti-inflammatory activity reports of metformin (Oliveira et al., 2016; Ou et al., 2018; Inayat et al., 2019; Kanigur Sultuybek et al., 2019), and increased cellular survival after an insult has been attributed to the metforminmediated increase in phosphorylation of the pro-survival/ anti-apoptotic kinase Akt (Ge et al., 2017; Tang et al., 2017). Metformin can also alter expression of a number of miRNAs involved in various cellular processes (Alimoradi et al., 2021), and alter the gut microbiome (Wu et al., 2017). Although metformin has been shown to reduce cell loss and improve cognitive outcome following moderate-to-severe $\mathrm{TBI}$, it has not been examined whether metformin can reduce the pathophysiology of rmTBI in which overt damage is not observed (Hill et al., 2016; Tao et al., 2018; Taheri et al., 2019; Rahimi et al., 2020).

By virtue of its impact on inflammation, growth, cell survival, and metabolic signaling cascades, we hypothesized that metformin would be efficacious in reducing $\mathrm{rmCHI}-$ related pathologies. To test this, we administered metfor$\mathrm{min}$ to $\mathrm{rmCH}$ animals $30 \mathrm{~min}$ after each injury (once a day for four consecutive days). Our results show that daily postinjury metformin administration reduced axonal damage, reduced inhibitory neuron loss, and enhanced ATP-

This work was supported in part by grants from the National Institutes of Health (NS086301, NS101686), and funds made available by the Gilson Longenbaugh Foundation/Mission Connect to P.K.D. Salary support for E.L.U. was provided by a T32 grant (2T32GM008792-16) from National Institute of General Medical Sciences.

${ }^{\star}$ E.L.U. and J.B.R. contributed equally to this work.

M. J. Hylin's present address: Department of Psychology, Southern Illinois University, Carbondale, IL 62901.

M. E. Maynard's present address: Department of Electrical and Computer Engineering, University of Houston, Houston, TX 77204.

Correspondence should be addressed to Pramod K. Dash at p.dash@ uth.tmc.edu.

https://doi.org/10.1523/ENEURO.0421-21.2021

Copyright @ 2021 Underwood et al.

This is an open-access article distributed under the terms of the Creative Commons Attribution 4.0 International license, which permits unrestricted use, distribution and reproduction in any medium provided that the original work is properly attributed. linked respiration in the hippocampi of $\mathrm{rmCH}$ mice. Furthermore, motor and memory dysfunction were significantly reduced in $\mathrm{rmCH}$ animals that received metformin. These results suggest that further studies may be warranted to determine whether metformin treatment after an $\mathrm{mTBI}$ may be beneficial in a clinical setting.

\section{Materials and Methods}

\section{Animals}

C57BI/6 male mice (15 weeks of age) were single housed on a 12/12 h light/dark cycle, with ad libitum access to food and water. Experiments were performed during the light cycle. As C57BL/6 male mice are separated by the vendor at 12 weeks of age (The Jackson Laboratory), mice were individually housed. All experimental procedures were conducted in accordance with the Guide for the Care and Use of Laboratory Animals of the National Institutes of Health, and approved by the UTHealth McGovern Medical School Animal Care and Use Committee.

\section{Repeat closed head injury (CHI)}

Mild CHls (mCHls) were delivered essentially as have been described previously (Mouzon et al., 2012; Hylin et al., 2013; Maynard et al., 2020). Male C57BL/6 mice (20$25 \mathrm{~g})$ were initially anesthetized with $5 \%$ isoflurane in a 1:1 $\mathrm{O}_{2} / \mathrm{N}_{2} \mathrm{O}$ mixture, mounted on a stereotaxic frame, and anesthesia was then maintained with a $2.5 \%$ isoflurane and $1: 1 \quad \mathrm{O}_{2} / \mathrm{N}_{2} \mathrm{O}$ mixture via a face mask. A midline incision was made and the soft tissue reflected to expose the skull. Anesthesia was discontinued, and the mouse was quickly transferred to a foam pad and positioned to make the head level with the body. At $40 \mathrm{~s}$ after discontinuation of anesthesia (a time point at which mice have typically regained their tail withdrawal reflex), a single impact was applied to the skull using a metal impactor tip ( $5 \mathrm{~mm}$ in diameter) driven at a velocity of $5.0 \mathrm{~m} / \mathrm{s}$ to a depth of 1.0 $\mathrm{mm}$. The center of the tip was located midway between $\lambda$ and bregma, over the sagittal suture. Immediately following the injury, the animals were monitored for apnea, and when normal breathing was observed, the scalp was closed using sterile surgical staples. Animals with obvious skull fractures $(\sim 15 \%)$ were excluded from this study. Mice received one injury/day for four consecutive days. Sham mice received daily anesthesia but were not injured.

\section{Metformin administration}

Metformin hydrochloride was dissolved in sterile saline at a concentration of $50 \mathrm{mg} / \mathrm{ml}$. Metformin was injected intraperitoneally at a dose of $250 \mathrm{mg} / \mathrm{kg} 30 \mathrm{~min}$ after each $\mathrm{CHI}$. Vehicle controls received an equal volume of sterile saline $(100 \mu \mathrm{l})$, injected $30 \mathrm{~min}$ after each injury. As a number of studies have examined the effects of metformin in naive animals, metformin was not administered to our sham controls to minimize the number of animals used in this study (Potter et al., 2010; Pintana et al., 2012; Li et al., 2019; Thinnes et al., 2021). 


\section{Measurement of plasma and brain metformin concentration}

For determining plasma and brain metformin concentrations, uninjured mice were intraperitoneally injected with $250 \mathrm{mg} / \mathrm{kg}$ metformin. Metformin has been reported to have plasma half-life of 2-6 $\mathrm{h}$ in mice (Kinaan et al., 2015). Six hours after injection, animals were euthanized and blood was collected. Their brains were then removed, and hippocampal, cortical, and cerebellar tissues dissected, weighed, and homogenized in water at $0.3 \mathrm{mg} / \mathrm{ml}$ $(w / v)$. Methanol $(400 \mu l)$ and acetonitrile $(500 \mu l)$ were added to $100 \mu \mathrm{l}$ homogenate, vortexed $60 \mathrm{~s}$, then incubated for $10 \mathrm{~min}$ at room temperature (RT). The solution was centrifuged at $20,000 \times g$ for $10 \mathrm{~min}$ at RT, and the supernatant removed and passed through a $0.45 \mu \mathrm{m}$ nylon syringe filter. The solution was dried at $45^{\circ} \mathrm{C}$ in a vacuum centrifuge, and resuspended in $120 \mu \mathrm{l}$ mobile phase (see below). Chromatography was conducted using a Shimadzu Nexera UPLC with dual LC-30AD pumps and an integrated Prominence degasser (DGU20A). The mobile phase consisted of a 90:10 mixture of $0.15 \mathrm{~m}$ ammonium acetate ( $\mathrm{pH} 5.5)$ and acetonitrile filtered through a $0.22 \mu \mathrm{m}$ nylon membrane. Separation was conducted on a Discovery HS F5-5 $(15 \mathrm{~cm} \times 4.6 \mathrm{~mm}, 5 \mu \mathrm{m})$ column at a rate of $1 \mathrm{ml} / \mathrm{min}$. Detection of metformin $(40 \mu \mathrm{l}$ injection volume) was conducted using a Prominence UV/ VIS detector (SPD-20A) at $236 \mathrm{~nm}$. For analysis of metformin in plasma, $100 \mu \mathrm{l}$ was deproteinized with the methanol:acetonitrile as described above. A standard curve was prepared by spiking naive extracts $(100 \mu \mathrm{l}$ each) with a known amount of metformin $(0.23,0.47,0.94$, $1.88,3.75,7.5$, or $15 \mathrm{nmol})$, processed as described above, and subsequently used to generate a standard curve that was used to calculate the concentration of metformin in the experimental samples. Spike-in assays revealed that the recovery from tissue and serum were $95 \%$ and $79 \%$, respectively. Calculations were corrected based on recovery.

\section{Immunohistochemistry}

Mice were deeply anesthetized using sodium pentobarbital $(100 \mathrm{mg} / \mathrm{kg})$. Once the animal failed to respond to foot and tail pinch, the animal was transcardially perfused with PBS followed by $4 \%$ paraformaldehyde in PBS. Brains were removed, postfixed overnight in perfusant, then cryoprotected in a $30 \%$ sucrose solution in PBS. Coronal brain sections $(40 \mu \mathrm{m})$ were prepared using a cryostat. Sections containing the dorsal hippocampus (bregma -1.58 to $-2.30 \mathrm{~mm}$ ) were used for analysis. Immunohistochemistry was performed by incubating brain sections with primary antibodies $(1 \mu \mathrm{g} / \mathrm{ml})$ overnight at $4^{\circ} \mathrm{C}$ in a solution consisting of PBS with $0.25 \%$ Triton X-100 (PBST), 2.0\% BSA, and 2.5\% normal goat or horse serum. After extensive washing in PBST, tissue sections were incubated for $1 \mathrm{~h}$ in species-specific secondary antibodies conjugated to Alexa Fluors. Sections were washed in PBST, mounted on microscope slides, coverslipped with Fluoromount G (Thermo Fisher Scientific), and visualized using epifluorescence detection. Images were captured using a Retiga 6000 camera with settings that remained consistent across groups. Immunoreactivity in the hippocampus was quantified using ImageJ by carefully outlining the hippocampus on three sections/animal and determining mean fluorescence signal intensity. The corpus callosum and hippocampal commissure $( \pm 0.5$ $\mathrm{mm}$ from midline) were combined for analysis.

\section{Silver staining}

Silver staining was conducted on free-floating sections using a kit from FD Neurotechnologies following the vendor instructions. Processed sections were mounted to glass slides, clarified using xylene, and coverslipped with Fluoromount $\mathrm{G}$ (Thermo Fisher Scientific). Slides were examined using an inverted microscope with bright-field capabilities. Images were captured using settings that remained consistent across groups. The corpus callosum and hippocampal commissure $( \pm 0.5$ $\mathrm{mm}$ from midline) were outlined on three sections/animal using ImageJ, and the calculated mean optical densities averaged and used for comparison across groups.

\section{Capillary westerns and analysis}

Mice were euthanized and hippocampal tissues dissected under ice cold artificial CSF (aCSF; $120 \mathrm{~mm} \mathrm{NaCl}$, $3.5 \mathrm{~mm} \mathrm{KCl}, 1.3 \mathrm{CaCl}_{2} \mathrm{mM}, 1 \mathrm{~mm} \mathrm{MgCl} 2,0.4 \mathrm{~mm} \mathrm{KH}_{2} \mathrm{PO}_{4}$, $5 \mathrm{~mm}$ HEPES, and $10 \mathrm{~mm}$ D-glucose; $\mathrm{pH}$ 7.4) and snap frozen on dry ice. Total protein homogenates were prepared using a Potter-Elvehjem homogenizer in lysis buffer containing $10 \mathrm{~mm}$ Tris- $\mathrm{HCl}, \mathrm{pH}$ 7.4, 1 mм EDTA, 1 mm EGTA, 1 $\mathrm{mm} \mathrm{Na}_{3} \mathrm{VO}_{4}, 5 \mathrm{~mm} \mathrm{NaF}, 5 \mathrm{~mm} \mathrm{Na} \mathrm{MoO}_{4}, 1 \mathrm{~mm} \mathrm{DTT}$, and $1 \times$ protease and phosphatase inhibitor cocktails (Thermo Fisher Scientific). Total protein concentration was measured by BCA assay using BSA as the reference standard. Sample aliquots were diluted into $1 \times$ sample buffer and protein content equalized. Target proteins were quantified using an automated capillary immunoassay system (Wes system; Protein Simple). Immunoreactivity was detected with a luminol-peroxide solution and a series of timed exposures were collected. The images were analyzed using Compass for SW (version 3.1.7; Protein Simple). Results were normalized against $\beta$-actin and presented as percent control.

\section{Tissue respiration}

Respiration measurements of brain biopsy punches were performed using an XF96 Extracellular Flux Analyzer (Seahorse Bioscience). At the indicated time points after injury, brains were rapidly removed and immersed in icecold $\left(4^{\circ} \mathrm{C}-5^{\circ} \mathrm{C}\right)$ aCSF that had been oxygenated for $1 \mathrm{~h}$ with $95 \% \mathrm{O}_{2}: 5 \% \mathrm{CO}_{2}$. Coronal sections $(225 \mu \mathrm{m})$ were cut using a Mcllwain tissue chopper (Ted Pella. Inc.), then transferred to a holding chamber containing room temperature $\left(\sim 23^{\circ} \mathrm{C}\right)$ continuously oxygenated aCSF and incubated for at least $30 \mathrm{~min}$. Before making tissue punches from the structures of interest, sections were individually transferred to a biopsy chamber containing freshly oxygenated aCSF, then $0.5-\mathrm{mm}$ diameter punches were excised using a stainless-steel biopsy punch needle 
(WellTech Rapid-Core). Punches were ejected directly into a XF96 Cell Culture Microplate (101085-004; Seahorse Bioscience) containing 100- $\mu$ room temperature assay media (aCSF supplemented with $4 \mathrm{mg} / \mathrm{ml} \mathrm{BSA}$ and $0.6 \mathrm{~mm}$ pyruvate). After loading all samples, the microplate was incubated in a $\mathrm{CO}_{2}$-free incubator at $37^{\circ} \mathrm{C}$ for $15 \mathrm{~min}$, followed by addition of $80 \mu \mathrm{l} /$ well of $37^{\circ} \mathrm{C}$ assay medium (bringing the total volume to $180 \mu \mathrm{l} /$ well). Punches were placed in the center of the measurement area of each well and the plate was returned to the incubator. Assay drugs were loaded into the Seahorse XFe96 Extracellular Flux Assay kit as indicated below. Drugs were prepared at $10 \times$ working concentrations in oxygenated aCSF ( $\mathrm{pH}$ 7.4) and delivered sequentially to achieve final concentrations of port A: oligomycin $(25 \mu \mathrm{g} / \mathrm{ml})$, port $\mathrm{B}$ : FCCP + pyruvate (7.5 $\mu \mathrm{m}$ and $7.7 \mathrm{~mm}$, respectively), and port $\mathrm{C}$ : antimycin $\mathrm{A}+$ rotenone $(10 \mu \mathrm{M}$ and $5 \mu \mathrm{M}$, respectively). The dose of each of these reagents was based on optimization experiments to achieve maximum inhibition. The duration of sampling time [for calculating the oxygen consumption rate (OCR)] for each condition was determined to allow the effect of each drug to reach a steady state. Wells with low basal activity $(<20 \mathrm{pmol} / \mathrm{min}$ OCR), and/or failing to respond to FCCP/pyruvate, were excluded from analysis.

\section{Mitochondria isolation and respiration measurement}

Mitochondria from brain tissues were isolated using Percoll density gradient centrifugation as previously described (Sims and Anderson, 2008; Sekine et al., 2015). Hippocampi were rapidly removed while submerged under ice-cold aCSF, rinsed with cold isolation buffer (10 mm EDTA, $100 \mathrm{~mm}$ Tris, and 12\% Percoll solution; $\mathrm{pH}$ 7.4), and homogenized in $3 \mathrm{ml}$ isolation buffer using a Dounce homogenizer (pestle A: eight strokes; pestle B: eight strokes). A small fraction of each homogenate was removed for determining protein concentration. The remaining homogenate was then layered onto a discontinuous Percoll gradient (26\% and $40 \%$ Percoll) and centrifuged at $4^{\circ} \mathrm{C}$ for $10 \mathrm{~min}$ at $30,700 \times \mathrm{g}$. The enriched mitochondrial fraction was removed from the $26 \%: 40 \%$ interface, transferred to individual centrifuge tubes, and diluted 1:4 with isolation buffer. Mitochondria were then pelletized by centrifugation $\left(16,700 \times g\right.$ at $\left.4^{\circ} \mathrm{C}\right)$ for $10 \mathrm{~min}$. The supernatant was discarded and the pellet suspended in mitochondrial assay solution (MAS; $70 \mathrm{~mm}$ sucrose, $220 \mathrm{~mm}$ mannitol, $10 \mathrm{~mm} \mathrm{KH} \mathrm{KO}_{4}, 5 \mathrm{~mm} \mathrm{MgCl}_{2}, 2 \mathrm{~mm}$ HEPES, and $1 \mathrm{~mm}$ EGTA) with substrates (10 mm pyruvate and $5 \mathrm{~mm}$ malate) and $0.2 \%$ BSA. An equal volume of suspension (containing $1 \mu \mathrm{g}$ of mitochondrial protein) was dispensed into individual wells of an Agilent XF96 cell culture microplate and centrifuged $\left(2000 \times g\right.$ at $\left.4^{\circ} \mathrm{C}\right)$ for $30 \mathrm{~min}$. Assay medium was added to the wells containing mitochondria to bring the final volume to $180 \mu \mathrm{l}$ before the plate being incubated at $37^{\circ} \mathrm{C}$ for $30 \mathrm{~min}$ and transferred to the analyzer for analysis. For assessing the various aspects of mitochondrial respiration, inhibitor/uncoupler stocks were loaded into the drug ports of a hydrated sensor cartridge in the following order: (1) oligomycin (2.5 $\mathrm{g} / \mathrm{ml}$ final), (2) FCCP (4 $\mu \mathrm{m}$ final), and (3) antimycin A (4 $\mu \mathrm{M}$ final) + rotenone (2 $\mu \mathrm{m}$ final). The assay protocol consisted of a minimum of three cycles of OCR measurements for each measurement period. Each cycle consisted of a 2-min "mix" period and 2-min "wait" period, followed by a 3-min "measure" period.

\section{Vestibulomotor and motor functions}

Foot-fault and beam balance tasks were used to determine an animal's postinjury vestibulomotor and motor performance on three consecutive days, beginning $24 \mathrm{~h}$ after the last injury as described previously (Varma et al., 2002; Tehranian et al., 2008). Foot-fault was evaluated by placing the animal on a wire grid $(1 \times 1 \mathrm{~cm})$ and the number of foot misplacements out of a total of 50 steps were counted. A fault was defined as when a front paw missed and appeared below the plane of the wire grid. For the beam balance procedure, the animal was placed on the stationary beam for a period of $60 \mathrm{~s}$. A trial ended, and the time was recorded, when the animal either fell off the beam, or $60 \mathrm{~s}$ had elapsed. Foot-fault and beam balance tests were repeated three times each day to give an average daily score.

\section{Novel objection recognition (NOR)}

Animals were habituated to the empty training chamber $(30 \times 30 \mathrm{~cm})$ for two 10 -min periods per day for $2 \mathrm{~d}$. On the third day, training was conducted by placing two identical objects in the box, and the animal was allowed to freely explore for $10 \mathrm{~min}$. Twenty-four hours later, the animal was tested for its long-term memory by replacing one of the objects in the chamber with a new object of a different shape, and allowed to again freely explore the objects for $10 \mathrm{~min}$. Trials were video recorded and the time spent exploring each object during the familiarization period and the memory test was tracked by an experimenter blinded to group designation. To eliminate potential object biases, the objects used in the familiarization and testing phases were previously verified as being equally interesting to naive mice. The choice of familiar and novel objects, and their placement in the chamber, was randomized across animals.

\section{Context discrimination}

Context discrimination was conducted by first preexposing animals for 10 min to two different contexts. These contexts shared certain features in common (background noise, horizontal grid floor, animal handling to and from the room), but differed in others (cues, floor color, shape, and scent). Animals were given two 3-min preexposure trials (one trial in each of the two different contexts). After the preexposure, one context was designated as the "shock" cage in which animals received a $2 \mathrm{~s}, 1.0 \mathrm{~mA}$ shock at the end of the 3-min trial. The other context was designated as the "safe" cage in which no shock was administered. The designation of the "safe" versus "shock" context, and the exposure order (e.g., safe then shock, or shock then safe), was randomized across animals. Twenty-four hours later, discrimination between the safe and shock contexts was assessed by monitoring freezing behavior while the animal explored each of the two 

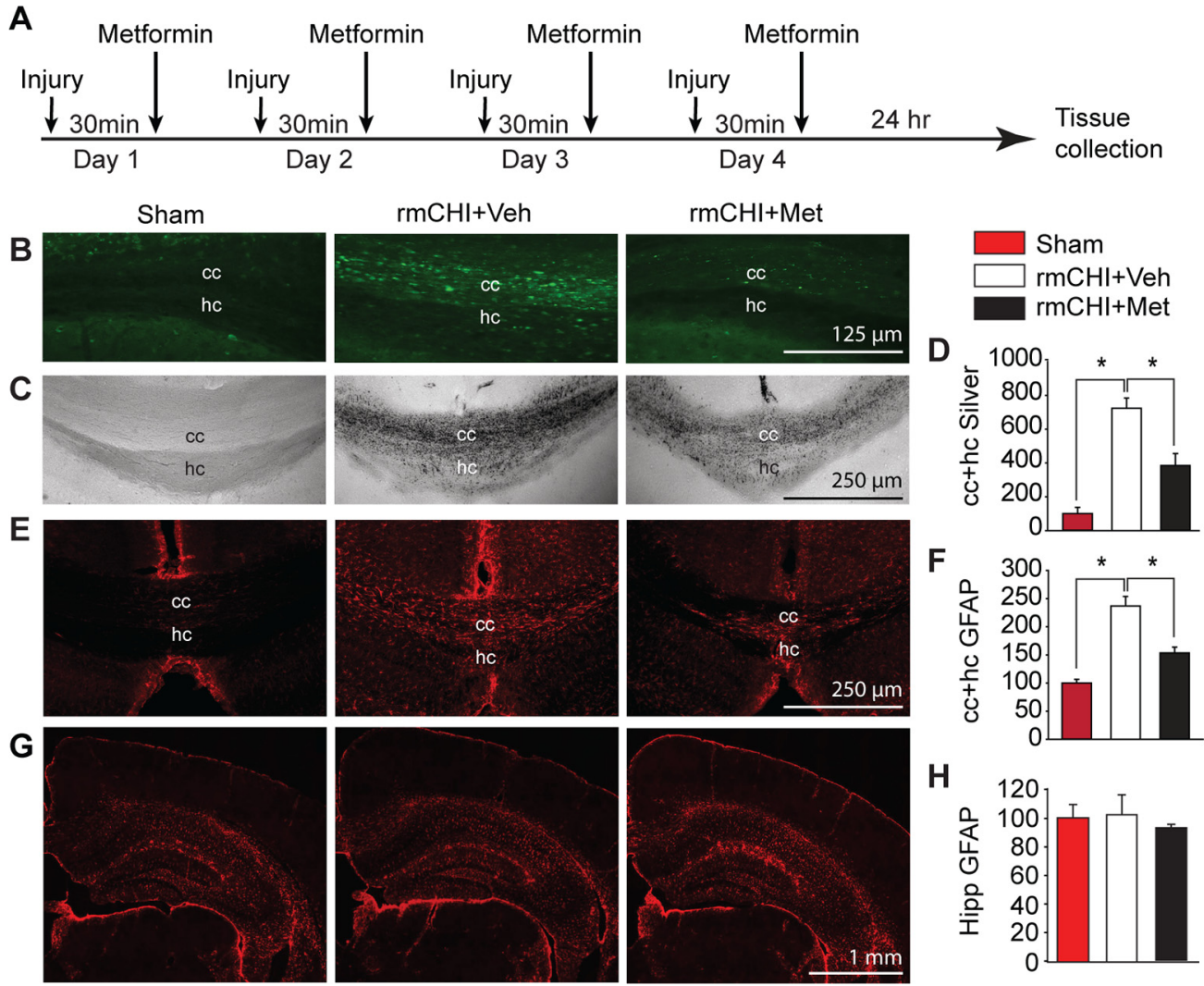

Figure 1. Postinjury metformin administration reduced $\mathrm{rmCH}$-triggered axonal damage and astrogliosis. $\boldsymbol{A}$, Schematic showing the injury and drug treatment paradigm. Representative photomicrographs showing (B) APP accumulation and $(\boldsymbol{C})$ enhanced silver impregnation in the corpus callosum (cc) and hippocampal commissure (hc) of a sham, a rmCHI+Veh, and a (rmCHI+Met) mouse. $\boldsymbol{D}$, Summary graph showing that $\mathrm{rmCHI}$ significantly increased silver impregnation in the $\mathrm{cc}$ and hc, which was reduced in animals treated with metformin. $\boldsymbol{E}$, Representative images of glial fibrillary acidic protein (GFAP) immunoreactivity showing increased reactive astrogliosis in the $\mathrm{cc}$ and $\mathrm{hc}$ of a rmCHI+Veh mouse, and reduced staining in injured a rm+Met mouse, as compared with sham. $\boldsymbol{F}$, Summary data for GFAP immunoreactivity in the cc + hc fiber tracts. $\boldsymbol{G}$, Images of hippocampi and parietal cortex from a sham, an rmCHI+Veh mouse, and an rmCHI+Met mouse demonstrating GFAP immunoreactivity. $\boldsymbol{H}$, Summary data for GFAP immunoreactivity in the hippocampus. Data are presented as the mean $\pm \mathrm{SEM}$; ${ }^{*} p<0.05$ by one-way ANOVA.

chambers ( 3 min each). The difference in freezing time in the "shock" versus "safe" cage was used as a measure of context fear discrimination.

\section{Experimental design and statistical analyses}

The number of animals used for each analysis are listed in the corresponding result section. Replication of biochemical and histologic data were conducted as described for each technique in the applicable Materials and Methods section. Data were statistically analyzed using Sigma Plot 12.0. All data were subjected to a ShapiroWilk test for normality and a Spearman rank correlation for equal variance before statistical comparison. For respiration measurements, a one-way ANOVA was used to compare across groups at a single time point. Foot fault, beam balance and context fear discrimination were analyzed across days and groups using two-way repeated measures ANOVAs. Both group main and interactions of group and time were considered indicators of group differences. Where applicable, Bonferroni-corrected post hoc comparisons were made. For the NOR task, the percent of time spent with the novel compared with familiar object was analyzed within groups using paired, twotailed Student's $t$ tests. All data are reported as mean \pm $\mathrm{SEM}$, and $p$ values were deemed statistically significant if $p<0.05$.

\section{Results}

\section{Metformin and axonal pathologies after $\mathrm{rmCHI}$}

The timeline for injury, drug administration, and tissue collection is shown in Figure $1 A$. Metformin $(250 \mathrm{mg} / \mathrm{kg})$ or an equal volume of vehicle was administered via intraperitoneal injection $30 \mathrm{~min}$ after each injury. This dose was based on previous studies that used metformin in mice (Lengyel et al., 2015; Hill et al., 2016; Karise et al., 2019; Wang et al., 2020a). After correction for body surface area (Nair and Jacob, 2016), this dose is equivalent to a $23 \mathrm{mg} / \mathrm{kg} / \mathrm{d}$ dose in humans, consistent with the guidance for dosing in type 2 diabetes $(1500-2500 \mathrm{mg} / \mathrm{d}$ for an 80-kg person).

Previous clinical and experimental studies have reported that mild TBI causes damage to major white matter tracts in the brain (Bennett et al., 2012; Bramlett and 
Dietrich, 2015; Palacios et al., 2020), including the corpus callosum. To examine whether metformin reduces corpus callosum damage, tissue sections from sham, rmCHI mice $+250 \mathrm{mg} / \mathrm{kg}$ metformin, and $\mathrm{rmCHI}+$ Veh $(30 \mathrm{~min}$ after each injury) were examined for APP immunoreactivity, an indicator of axonal damage, $24 \mathrm{~h}$ after the last injury (Stone et al., 2004; Marmarou et al., 2005). Figure 1B shows representative photomicrographs of APP immunoreactivity within the corpus callosum/hippocampal commissure region in tissue sections from a sham, an $\mathrm{rmCHI}$ mouse-treated with vehicle, and an $\mathrm{rmCHI}$ mouse treated with metformin. Numerous APP-immunopositive axons were detected in the corpus callosum and hippocampal commissure in the rmCHI+Veh animals. APP immunoreactivity was markedly reduced in animals that received the postinjury metformin treatment, suggesting reduced axonal injury. We then performed silver staining to further examine the extent of axonal injury in these fiber tracts. The representative photomicrographs of silver-stained brain sections presented in Figure $1 C$ show that, consistent with the accumulation of APP, $\mathrm{rmCH}$ resulted in enhanced silver impregnation in the corpus callosum and hippocampal commissure, while staining was reduced in rmCHI animals acutely treated with metformin (Fig. 1C). Quantification ( $n=4 /$ group) of silver impregnation within these white matter tracts showed there was a significant increase in axonal damage after $\mathrm{rmCHI}(F=22.806$, $p<0.001$ ) that was significantly attenuated by metformin treatment (Fig. 1D).

Astrocytes are activated in response to injury and are thought to contribute to evolving brain pathology by taking up extracellular glutamate, regulating inflammation, and forming a glial scar that can impede regeneration of damaged axons (Floyd and Lyeth, 2007; Burda et al., 2016). Increased GFAP immunoreactivity (an indicator of activated astrocytes) can be seen in the corpus callosum and hippocampal commissure of injured animals $24 \mathrm{~h}$ after the last injury, indicating astrocyte activation (Fig. $1 E$ ). Quantification ( $n=4 /$ group) of GFAP immunoreactivity in the corpus callosum and hippocampal commissure revealed that the injury-triggered increase in GFAP immunoreactivity was significantly reduced by acute postinjury metformin treatment $(F=32.925, p<0.001$; Fig. $1 F)$. Increased GFAP immunoreactivity was predominately observed in white matter tracts as GFAP immunoreactivity was not altered in either the hippocampus or injured cortex (Fig. 1G,H).

\section{rmCHI-triggered loss of hippocampal parvalbumin- positive inhibitory neurons and metformin treatment}

Consistent with the classification of the injury as mild, when tissue sections collected two weeks after rmCHI were immunostained for NeuN, no overt neuronal loss or tissue damage was observed (Fig. 2A). Higher magnification images of the hippocampus show that $\mathrm{rmCHI}$ did not cause visible neuronal loss nor disruption of the neuronal layers in either $\mathrm{rmCHI}$ mice treated with vehicle, or $\mathrm{rmCHI}$ mice treated with metformin, as compared with sham controls (Fig. 2B). Furthermore, no changes in the immunoreactivity for the synaptic proteins vGlut1 (Fig. $2 \mathrm{C}$ ) or
vGlut2 (Fig. 2D) were observed. Capillary western analysis ( $n=4$ /group) of hippocampal total protein extracts showed no significant changes in the immunoreactivities for postsynaptic density protein 95 (PSD95), synaptogyrin 1 (Syngr1), neuronal synaptobrevin (n-Syb), or synaptic vesicle protein 2 (SV2; Fig. 2E), in contrast to what has been observed after higher magnitudes of TBI (Ansari et al., 2008; Sen et al., 2017). Lastly, we detected no change in the number of doublecortin-positive newborn hippocampal neurons (examined $72 \mathrm{~h}$ after the last injury; $n=5 /$ group) as a result of repeat injury, or in response to metformin treatment after injury (Fig. 2F,H).

It has been suggested that inhibitory neurons, particularly parvalbumin-positive fast-spiking interneurons, are vulnerable to all magnitudes of TBI (Hsieh et al., 2017; Tucker et al., 2019; Broussard et al., 2020; Cantu et al., 2020; Carron et al., 2020). rmCHI has been demonstrated to result in the loss of hippocampal parvalbumin-positive interneurons (Tucker et al., 2019), while metformin treatment can enhance cell survival signaling in some experimental models (Ge et al., 2017; Tang et al., 2017). We therefore examined whether metformin administered post-rmCHI could mitigate parvalbumin-positive neuron loss. Figure $2 G$ shows representative images of parvalbumin immunostaining in the hippocampi from a sham, a two-week post-rmCHI mouse treated with vehicle, and a two-week post-rmCHI mouse treated with $250 \mathrm{mg} / \mathrm{kg}$ metformin after each injury. The summary data presented in Figure 2/ ( $n=3$ /group) shows that a significant injury-associated decrease in the number of parvalbumin-positive cells was detectable in the CA1/CA2 subfield $(F=9.476$, $p=0.014)$, the CA3 subfield $(F=54.355, p<0.001)$, and the dentate/hilar region $(F=22.622, p=0.002)$ two weeks after $\mathrm{rmCHI}$ in vehicle-treated mice. Postinjury treatment with metformin ameliorated the loss of parvalbumin immunostaining.

\section{Metformin and hippocampal mitochondrial function after rmCHI}

To examine the effect of $\mathrm{rmCHI}$ and postinjury metformin treatment on mitochondrial respiration, we measured OCR using tissue biopsy punches. A schematic of the experimental design is shown in Figure $3 A$. Dorsal hippocampal (containing stratum oriens, CA1 stratum pyramidale, and stratum radiatum) and parietal cortex (containing layers 2-6; AP $-4.52 \mathrm{~mm}, \mathrm{ML} 4-5 \mathrm{~mm}$ ) tissue punches were prepared from sham, $\mathrm{rmCHI}+$ Veh and $\mathrm{rmCHI}+$ Met mice (Fig. 3B). A representative OCR curve indicating the responses to various inhibitor injections used to interrogate different aspects of mitochondrial respiration is shown in Figure 3C. Basal OCR is determined by respiration measurement before any inhibitor injection. The ATP synthase inhibitor oligomycin blocks proton flux through ATP synthase (Complex V), reducing OCR to reveal respiration linked to ATP synthesis. The residual proton flux and related oxygen consumption after oligomycin addition to the reaction represents a measure of proton leak. The uncoupler FCCP, which abolishes the proton gradient, results in maximal OCR. Finally, the addition of rotinone (a Complex I inhibitor) and antimycin A (an inhibitor of cytochrome $c$ reductase) abolishes mitochondrial-mediated oxygen respiration. 

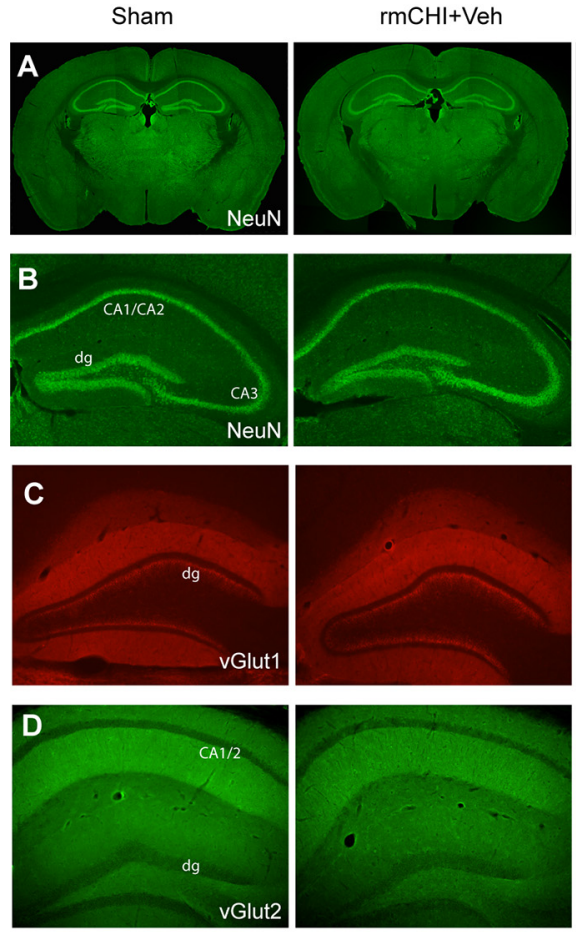
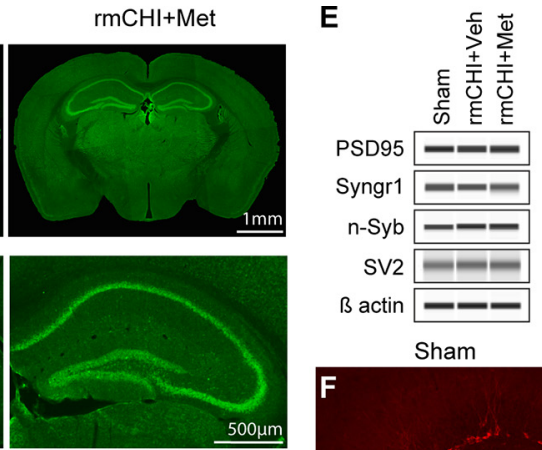

Sham
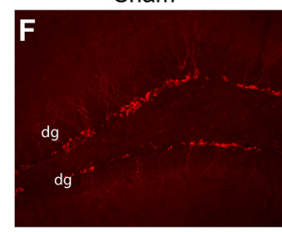
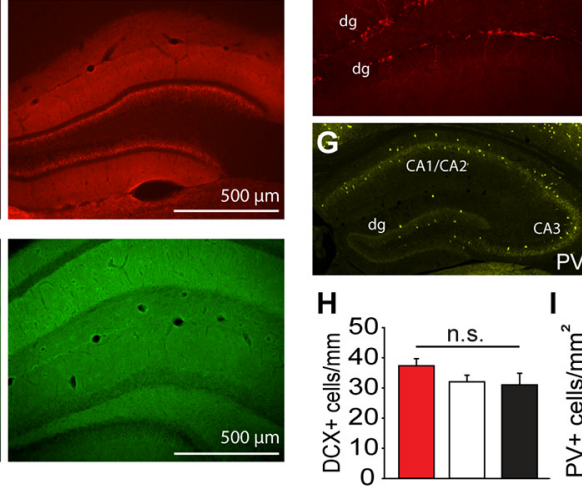

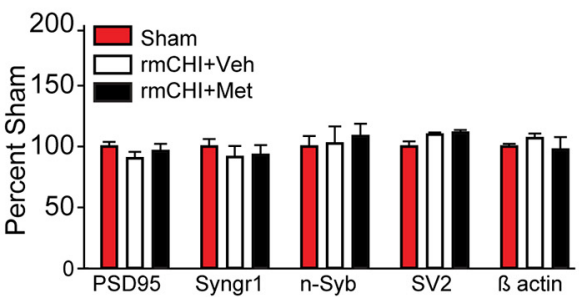

$\mathrm{rmCHI}+\mathrm{Veh}$
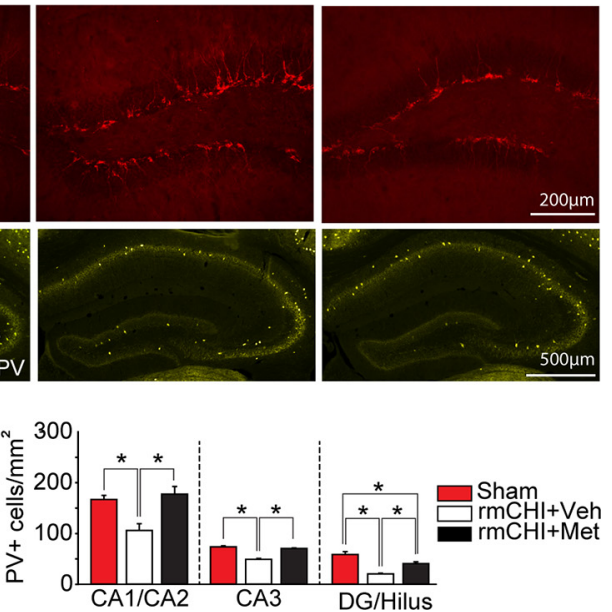

Figure 2. Metformin treatment preserves hippocampal parvalbumin-expressing cells after rmCHI. A, Montage images of coronal mouse brain sections and hippocampi from sham, two-week postinjury rmCHI mouse treated after each injury with vehicle $(\mathrm{rmCHI}+\mathrm{Veh})$, and a two-week postinjury $\mathrm{rmCHI}$ mouse treated after each injury with metformin (rmCHI+Met). Sections were immunostained with antibodies against $(\boldsymbol{A}, \boldsymbol{B})$ the neuronal marker NeuN, $(\boldsymbol{C})$ the synaptic vesicle protein Vesicular glutamate transporter 1 (vGlut1), and (D) the synaptic vesicle protein Vesicular glutamate transporter 2 (vGlut2). $\boldsymbol{E}$, Representative capillary western analyses and summary data showing that neither $\mathrm{rmCHI}$ nor postinjury metformin treatment had any demonstrable effect on the hippocampal levels of postsynaptic density protein 95 (PSD95), synaptogyrin 1 (Syngr1), neuronal synaptobrevin (n-Syb), or synaptic vesicle protein 2 (SV2). Representative photomicrographs showing ( $\boldsymbol{F}$ ) doublecortin (DCX) and (G) parvalbumin (PV) immunoreactivity in the hippocampus of sham, rmCHI+Veh, and $\mathrm{rmCHI}+$ Met mice. $\boldsymbol{H}$, Summary data $(n=4 / g r o u p)$ showing that $r m C H I$ had no statistical effect on the number of doublecortin-positive newborn neurons in the hippocampus when examined $3 \mathrm{~d}$ after injury. $\boldsymbol{I}$, Summary data ( $n=3 / g r o u p)$ showing that $\mathrm{rmCHI}$ reduced the number of PV-positive interneurons in all hippocampal regions examined. Metformin treatment reversed the loss of PV-positive interneurons in the CA1, CA2, and CA3 regions, and attenuated the loos in the DG/hilus. dg: dentate gyrus; ${ }^{*} p<0.05$ by one-way ANOVA.

Any remaining residual oxygen consumption after addition of rotinone/antimycin $\mathrm{A}$ is attributed to nonmitochondrial oxygen-consuming enzymes in the sample, such as oxidases.

The summary results $(n=6$ animals/group; 5 punches/region) shown in Figure $3 D$ indicate that $\mathrm{rmCHI}$ significantly increased proton leak in the dorsal hippocampus $2 \mathrm{~h}$ after the last injury $(F=6.765$; $p=0.005$; post hoc sham vs $\mathrm{rmCHI}+$ Veh: $p=0.035$ ). Proton leak was reduced by metformin treatment ( $\mathrm{rmCHI}+$ Veh vs rmCHI+Met: $p=0.005)$, and was accompanied by a significant increase in ATP-linked respiration $(F=5.201 ; p=0.015$; sham vs $\mathrm{rmCHI}+$ Met: $p=0.013$ ). Of note, these changes were not observed in mice that were euthanized $2 \mathrm{~h}$ after a single $\mathrm{CHI}$ (data not shown), and had normalized by $7 \mathrm{~d}$ postinjury (Fig. 3E). Nonmitochondrial respiration (oxygen consumption by enzymes such as monoamine oxidase, xanthine oxidase, etc.) in the hippocampus was not different $2 \mathrm{~h}$ after $\mathrm{rmCH}$, but was significantly enhanced $7 \mathrm{~d}$ after $\mathrm{rmCHI}(F=8.06 ; p=0.003$; Fig. $5 E)$.
Metformin treatment did not affect this delayed increase in nonmitochondrial respiration $(\mathrm{rmCHI}+\mathrm{Veh}$ vs rmCHI+Met: $p=0.452$ ). There were no significant changes in mitochondrial respiration detected in cortical punches taken at either $2 \mathrm{~h}$ (Fig. 3F) or $7 \mathrm{~d}$ (Fig. 3G) postinjury.

\section{High-dose metformin and mitochondrial Complex I}

Many studies have reported that concentrations of metformin in the millimolar range can decrease mitochondrial respiration by inhibiting Complex I activity (El-Mir et al., 2000; Detaille et al., 2002; Wheaton et al., 2014; Matsuzaki and Humphries, 2015; LaMoia and Shulman, 2021), although the physiological relevance of this inhibition remains controversial (Fontaine, 2018; Pecinová et al., 2019; LaMoia and Shulman, 2021). Consistent with previous results, we found that metformin concentrations higher than $2 \mathrm{~mm}$ significantly suppressed basal OCR in isolated hippocampal mitochondria $(F=55.5, p<0.001$; Fig. $4 A)$. This suppression could not be recovered by the addition of ADP, but could be overcome by 
A

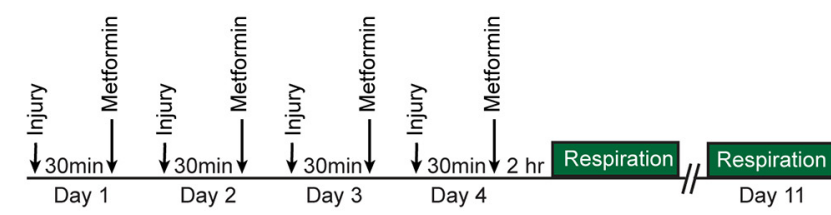

B

C
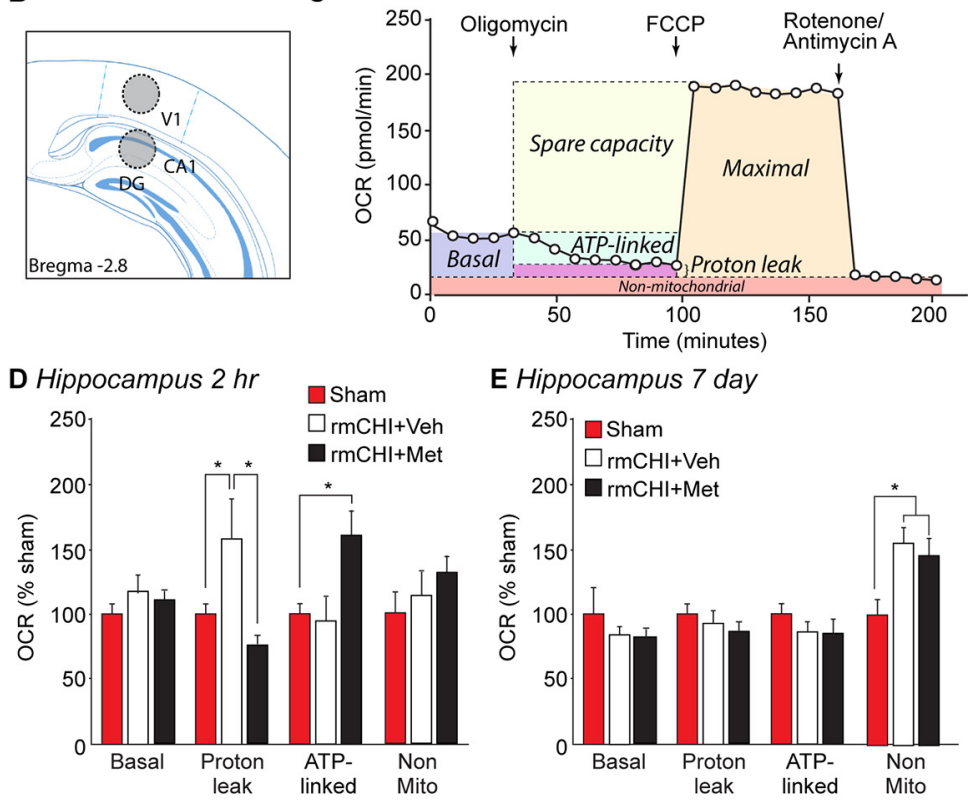

E Hippocampus 7 day

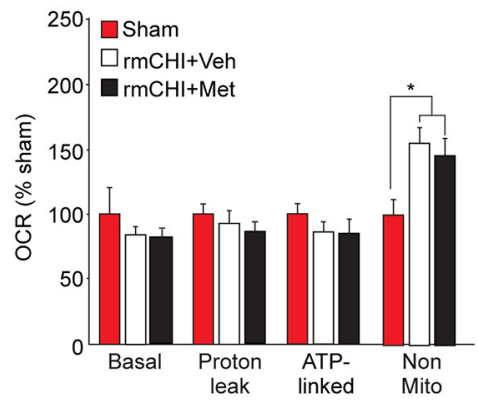

F Cortex $2 \mathrm{hr}$

G Cortex 7 day
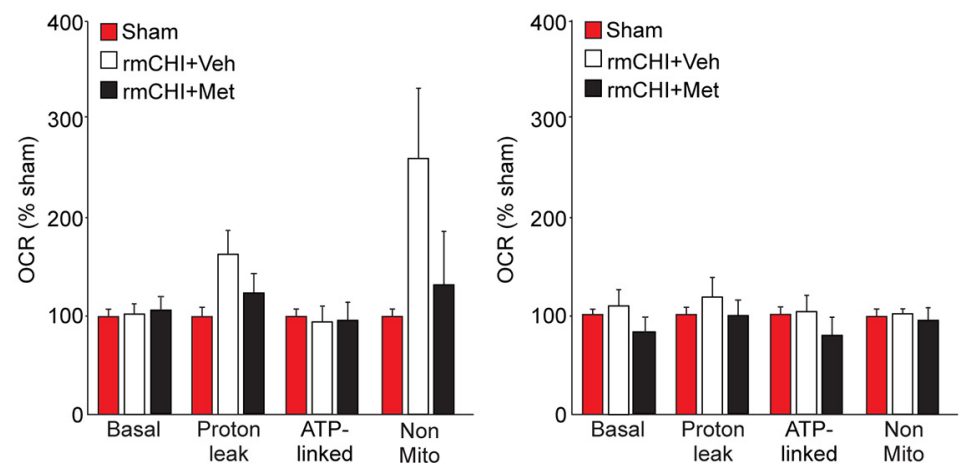

Figure 3. Postinjury metformin administration reduced mitochondrial proton leak and increased ATP-linked respiration in the hippocampus after rmCHI. $\boldsymbol{A}$, Timeline for injury (once daily for $4 \mathrm{~d}$ ), metformin administration, and respiration measurements either $2 \mathrm{~h}$ or $7 \mathrm{~d}$ after the final injury was given on the fourth day. B. Drawing of a coronal brain section showing the relative positions of the tissue punches taken for cortical and hippocampal tissue respiration measurements. $\boldsymbol{C}$, A representative trace of the oxygen consumption rate $(\mathrm{OCR})$ showing the different phases of mitochondrial respiration that can be identified using inhibitors. Changes in OCR resulting from the addition of the various mitochondrial inhibitors/uncouplers is used to determine the different components of mitochondrial (and nonmitochondrial) respiration. Summary results showing the effect of $\mathrm{rmCH}$ and metformin treatment on the various aspects of mitochondrial respiration in the hippocampus at $(\boldsymbol{D}) 2 \mathrm{~h}$ and $(\boldsymbol{E}) 7 \mathrm{~d}$ postinjury. Summary results showing the effects of $\mathrm{rmCHI}$ and metformin treatment on mitochondrial respiration in the cortex at $(\boldsymbol{F}) 2 \mathrm{~h}$ and $(\boldsymbol{G}) 7 \mathrm{~d}$ postinjury. Data are presented as the mean $\pm \mathrm{SEM} ;{ }^{*} p<0.05$ by one-way ANOVA.

the addition of the uncoupler FCCP (Fig. 4B). As ADP requires an intact membrane potential to increase OCR, this data supports the premise that at high doses, metformin inhibits Complex I thereby disrupting the proton gradient of mitochondria.

We measured the concentration of metformin reached in the brain after intraperitoneal administration to assess the possibility that it might be inhibiting Complex I activity.
Mice $(n=4)$ were intraperitoneally injected with $250 \mathrm{mg} / \mathrm{kg}$ metformin, and serum and brains were collected at $6 \mathrm{~h}$ for analysis of metformin using HPLC as described in Materials and Methods. This time point was chosen as it has been previously reported that metformin reaches its peak concentration in the brain at $6 \mathrm{~h}$ after administration, equivalent to the metformin concentration in the serum (Łabuzek et al., 2010). Representative chromatograms 


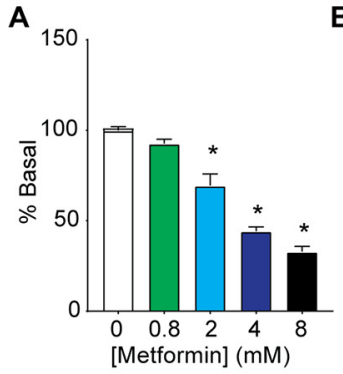

C

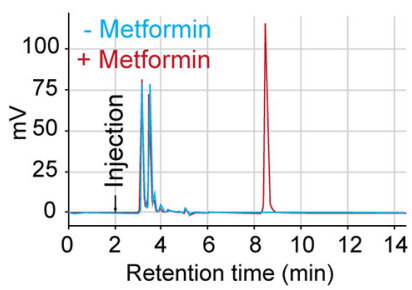

B

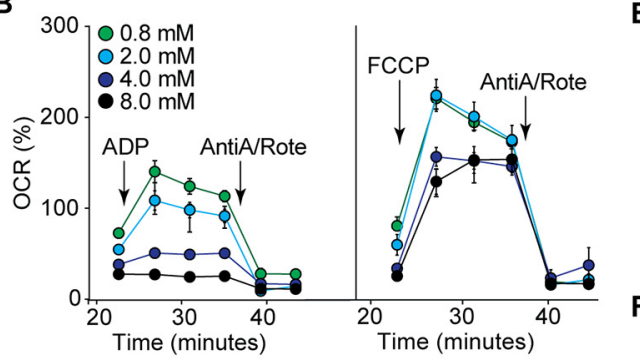

D

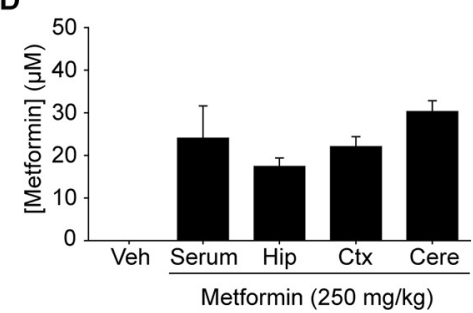

E

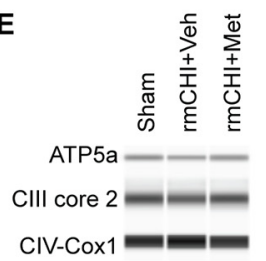

$\mathbf{F}$
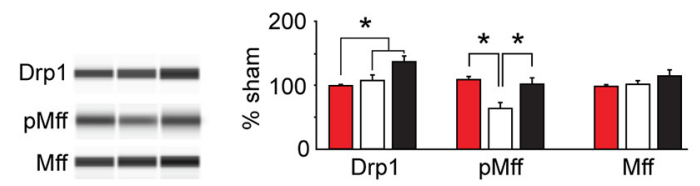

Opa1 $=$

Mfn2 $=-$

B-actin $=$

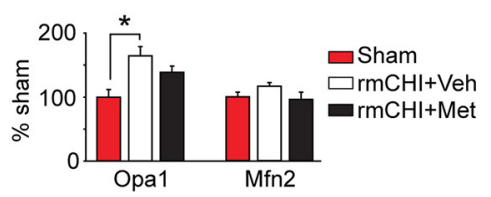

Figure 4. Metformin activates pathways involved in mitochondrial fission. $\boldsymbol{A}$, Summary data showing that $\geq 2 \mathrm{~mm}$ metformin present in the reaction buffer significantly inhibits basal respiration of isolated hippocampal mitochondrial; ${ }^{*} p<0.05$ by one-way ANOVA compared with vehicle (0 $\mathrm{mm}$ metformin). B, Addition of ADP, which requires an intact proton gradient to stimulate oxygen consumption, had no effect on mitochondria treated with $\geq 4 \mathrm{~mm}$ metformin. Trifluoromethoxy carbonylcyanide phenylhydrazone (FCCP), which uncouples oxygen consumption from ATP synthesis by disrupting the proton gradient, stimulated OCR at all metformin concentrations. C, Representative HPLC chromatographs of cortical tissue extracts in the absence (blue) and presence (red) of metformin. $\boldsymbol{D}$, Summary data showing the concentration of metformin in various tissues detected $6 \mathrm{~h}$ after intraperitoneal administration of $250 \mathrm{mg} / \mathrm{kg}$ to mice. Data are presented as the mean \pm SEM. $\boldsymbol{E}$, Representative capillary western analyses and summary data ( $n=5$ /group) showing that neither rmCHI nor metformin treatment altered the expression of components of the electron transport system $2 \mathrm{~h}$ after the last injury. ATP5a: ATP synthase F1 subunit $\alpha$; CIII core 2: cytochrome b-c1 complex subunit 2; CIVCOX1: mitochondrially encoded cytochrome $c$ oxidase I. $\boldsymbol{F}$, Representative capillary western analyses and summary data showing that $\mathrm{rmCHI}$ significantly decreases Mff phosphorylation and increases Opa1 levels compared with sham controls. Metformin treatment restored Mff phosphorylation and increased Drp1 levels. Drp1: dynamin 1-like protein; Mff: mitochondrial fission factor; Opa1: optic atrophy 1; Mfn2: mitofusin-2; ${ }^{*} p<0.05$ by one-way ANOVA.

from processed cortical tissue extracts in the absence (blue) and presence (red) of spike-in metformin show that metformin eluted with a retention time of 6.59 min after sample injection (Fig. 4C). The serum concentration of metformin was calculated to be $24.03 \pm 7.6 \mu \mathrm{m}$, comparable that reported in a previous study (Łabuzek et al., 2010). The concentrations of metformin in the hippocampus, cerebral cortex and the cerebellum ranged from 18 to $30 \mu \mathrm{m}$ (Fig. 4D).

\section{Metformin and mitochondrial signaling pathways after rmCHI}

Metformin has been demonstrated to increase mitochondrial biogenesis and alter mitochondrial dynamics (Kukidome et al., 2006; Wheaton et al., 2014; Jin et al., 2016; Izzo et al., 2017; Karise et al., 2019; Wang et al., 2019). We examined the expression levels of key components of the mitochondrial electron transport system by Capillary western analyses $2 \mathrm{~h}$ after the last injury. No significant differences in the immunoreactivity of ATP5a (ATP synthase subunit $\alpha ; F=0.126, p=0.883$ ), CIII core 2 (cytochrome b-c1 complex subunit 2; $F=0.173, p=0.843$ ), or CIV-COX1 (mitochondrially encoded cytochrome $c$ oxidase I; $F=2.387, p=0.134$ ) were observed after $\mathrm{rmCHI}$ $(\mathrm{rmCHI}+$ Veh) or metformin treatment $(\mathrm{rmCHI}+$ Met) as compared with sham controls ( $n=5 /$ group), suggesting repeated injury did not increase mitochondria biogenesis (Fig. 4E). In contrast, when signaling pathways involved in regulating mitochondrial dynamics were interrogated, we detected an injury-related significant decrease in phosphorylated mitochondrial fission factor (Mff; $F=7.717$, $p=0.008$ : sham vs rmCHI+Veh: $p=0.014)$, and a significant increase in Opa1 levels $(F=6.940, p=0.013$; sham vs $\mathrm{rmCHI}+$ Veh: $p=0.012$ ), suggesting that $\mathrm{rmCHI}$ decreased mitochondrial fission (Fig. 4F). Metformin administration attenuated the injury-related decrease in Mff phosphorylation ( $\mathrm{rmCHI}+$ Veh vs $\mathrm{rmCH}+$ Met: $p=0.018)$. Opa1 levels were found to be modestly decreased in response to metformin treatment, although this did not reach statistical significance $(\mathrm{rmCH}+\mathrm{Veh}$ vs $\mathrm{rmCHI}+$ Met: $p=0.150$; Fig. 4F). In addition, metformin treatment increased total Drp1 immunoreactivity in injured mice $(F=6.248$, $p=0.015 ; \quad \mathrm{rmCHI}+$ Veh vs $\mathrm{rmCHI}+$ Met: $p=0.040$ ). No change in the total level of $\mathrm{Mff}(F=1.703, p=0.223)$ or mitofusin-2 (Mfn2; $F=1.965, p=0.191$ ) was observed as a result of $\mathrm{rmCHI}$, or in response to metformin treatment.

\section{Metformin and vestibulomotor and motor function after $\mathbf{r m C H I}$}

We examined whether acute metformin treatment affected the vestibulomotor and motor dysfunctions resulting from $\mathrm{rmCHI}$ ( $n=10 /$ group). Vestibulomotor function 
A
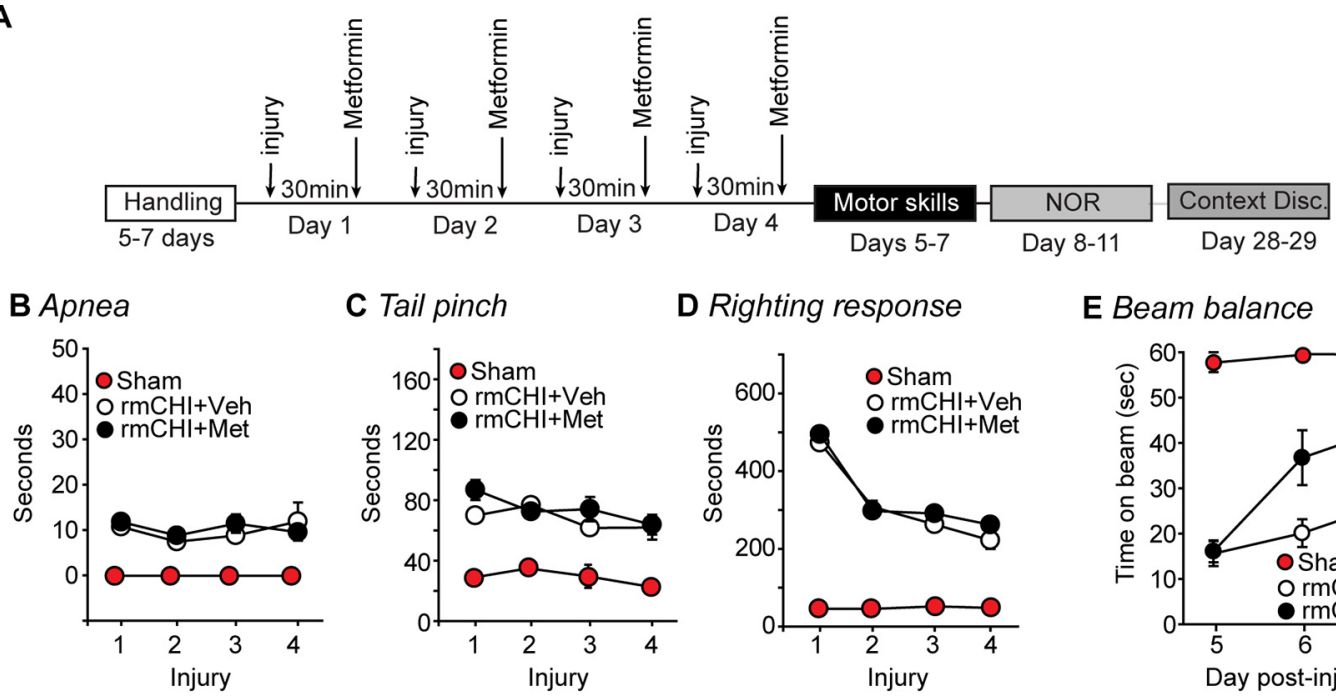

D Righting response

E Beam balance

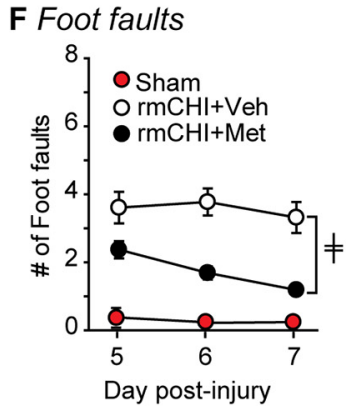

G NOR Familiarization
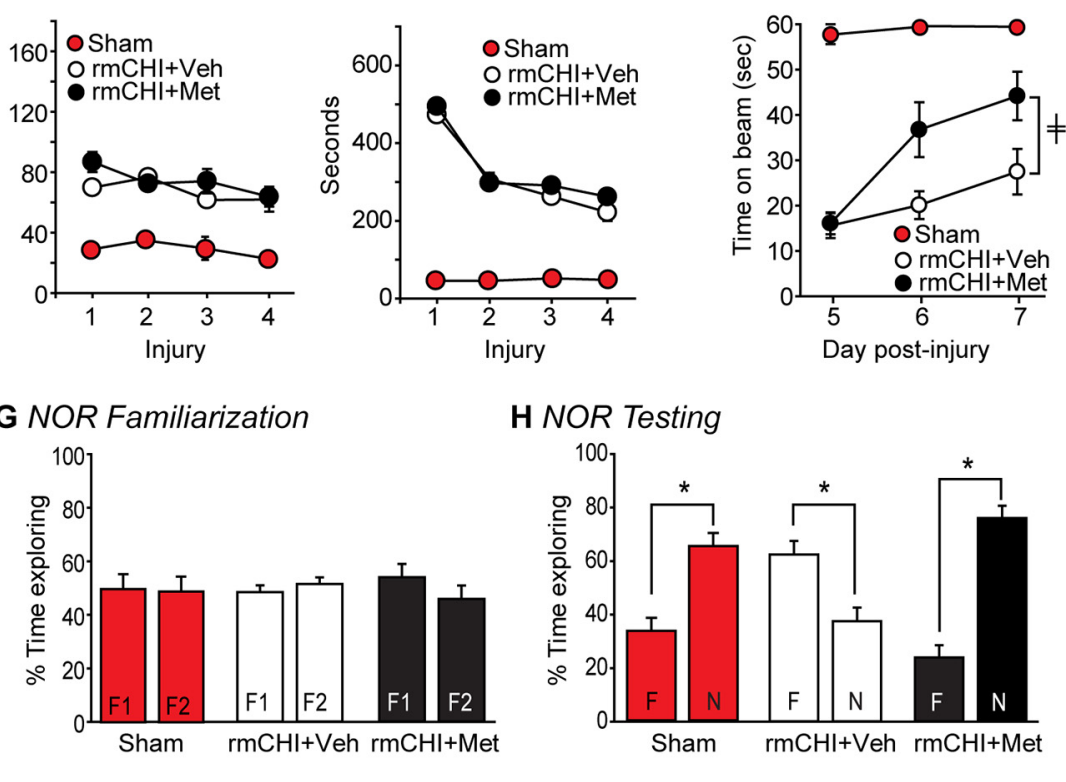

H NOR Testing

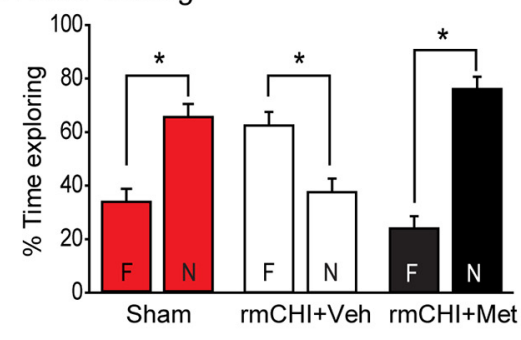

\section{Context Discrimination}
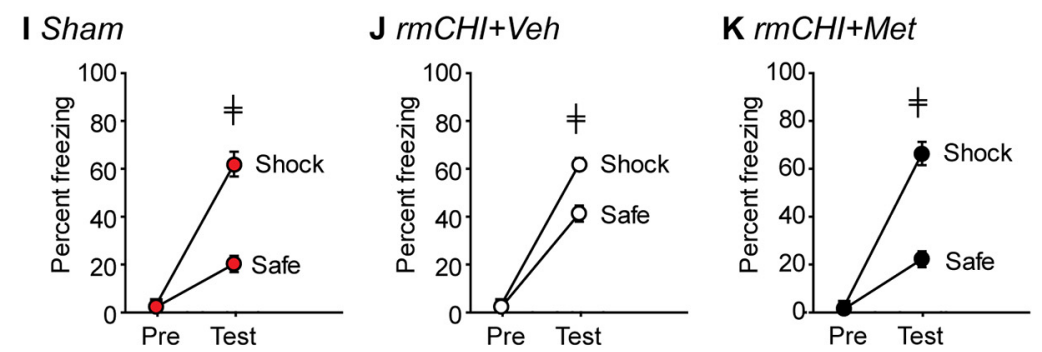

L Difference score

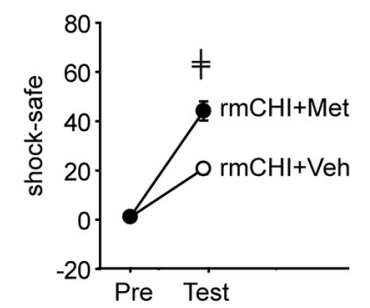

Figure 5. Postinjury administration of metformin after $\mathrm{rmCHI}$ reduced vestibulomotor, motor, and cognitive dysfunction. $\boldsymbol{A}$, Time line showing the experimental design. Sham, $\mathrm{rmCHI}+\mathrm{Veh}$, and $\mathrm{rmCHI}+\mathrm{Met}(250 \mathrm{mg} / \mathrm{kg})$ animals were tested immediately after injury for $(\boldsymbol{B})$ duration of apnea, $(\boldsymbol{C})$ suppression of tail pinch reflex, and $(\boldsymbol{D})$ latency to regain righting response. Vestibulomotor and motor performances of sham, $\mathrm{rmCHI}+\mathrm{Veh}$, and $\mathrm{rmCHI}+$ Met mice were tested using the $(\boldsymbol{E})$ beam balance and $(\boldsymbol{F})$ foot fault (grid walking) tasks. On days 8-11, animals were tested for cognitive performance in the NOR task. G, Percent time exploring the two identical objects (F1 and F2) used for familiarization in the NOR task. All groups equally explored both objects. $\boldsymbol{H}$, When tested for their object memory $24 \mathrm{~h}$ later, both sham and $\mathrm{rmCHI}+$ Met mice spent significantly more time exploring the novel object $(\mathrm{N})$ rather than the familiar one $(\mathrm{F})$, indicating intact recognition memory. $\mathrm{rmCHI}+$ Veh mice spent more time with the familiar object, an indication of perseveration. Performance of $(\boldsymbol{I})$ sham, $(\boldsymbol{J}) \mathrm{rmCHI}+\mathrm{Veh}$, and $(\boldsymbol{K}) \mathrm{rmCHI}+$ Met in the context discrimination task. $\boldsymbol{L}$, Comparison of the freezing differentials between "shock" and "safe" contexts in the $\mathrm{rmCHI}+$ Veh versus rmCHI+Met mice. Data are presented as the mean \pm SEM; $\ddagger p<0.05$ by two-way repeated measures ANOVA; ${ }^{*} p<0.05$ by paired $t$ test.

was tested using the beam balance task, and motor function using the foot fault task. These tests were conducted for three consecutive days beginning $24 \mathrm{~h}$ after the last injury administration (Fig. 5A). A group of uninjured sham mice $(n=10)$ that were anesthetized once a day for $4 \mathrm{~d}$ were used as baseline controls for comparison. Acute neurologic measures were recorded after each sham or injury surgery. rmCHI caused a significant increase in postinjury apnea $(F=19.201, p<0.001$; Fig. $5 B)$, a suppression of the tail reflex $(F=45.034, p<0.001$; Fig. $5 C)$, and increased latency to regain righting responses (interaction: $F=9.103, p<0.001$; Fig. $5 D$ ) when compared with sham controls. These acute neurologic changes did not differ between vehicle-treated and metformin-treated 
injured mice: duration of apnea $(p=0.788)$; duration of suppression of pain reflexes $(p=0.735)$; duration of suppression of righting responses $(p=0.529)$. Beginning $24 \mathrm{~h}$ after the last sham or injury surgery, vestibulomotor and motor function was tested once a day for $3 \mathrm{~d}$. Both vehicle- and metformin treated rmCHI groups ( $n=10 /$ group) displayed vestibulomotor dysfunction, as indicated by an inability to balance on a narrow beam (Fig. 5E). However, the $\mathrm{rmCHI}+$ Met treatment group showed significantly improved balance performance, indicated by longer latencies to fall off the balance beam when compared with vehicletreated $\mathrm{rmCHI}$ animals $(F=5.360, p=0.033$; Fig. 5E). Similarly, although both injured groups made more foot faults than sham controls, motor function was improved in the $\mathrm{rmCHI}+$ Met group, as evidenced by a significant decrease in the number of foot faults compared with vehicletreated injured mice $(F=5.313, p=0.010$; Fig. $5 F)$.

\section{Metformin and memory after rmCHI}

Beginning on day 8 postinjury, recognition memory was tested using the NOR task (Fig. $5 A$ ). Exploration of novelty (object or place) is an innate animal and human behavior. The results presented in Figure 5G show that all groups spent equivalent amounts of time exploring the two objects ( $F 1$ and $F 2$ ) during familiarization, indicating there was no preexisting bias for the objects, or their positions in the testing chamber. Twenty-four hours later, one of the familiar objects was replaced with a novel object to test recognition memory. Uninjured sham mice spent more time exploring the novel object $(\mathrm{N})$ than the familiar $(\mathrm{F})$ one $(p=0.014$; Fig. $5 H)$. In contrast, the $\mathrm{rmCHI}+$ Veh group spent more time exploring the familiar object, rather than the novel object $(p=0.034)$ indicating impaired recognition memory. Acute postinjury administration of metformin to $\mathrm{rmCHI}$ mice improved recognition memory $(p<$ 0.001 ; Fig. $5 H$ ), as indicated by animals spending significantly more time exploring the novel object. This performance by the metformin-treated $\mathrm{rmCHI}$ mice was comparable to that of sham-operated control mice.

Contextual fear discrimination task was administered beginning on day 28 postinjury (Fig. $5 A$ ). In this task, normal animals remain frozen for a longer duration of time in the chamber in which they had previously received a foot shock (shock chamber) as compared with a chamber in which they had not received a foot shock (safe chamber). Before foot shock, all groups displayed normal exploratory behaviors in both the safe and shock contexts, and did not assume a freezing posture (an indicator of fear). Figure $5 /$ shows that sham-operated controls quickly learn to differentiate between the two similar but distinct contexts, displaying significantly more freezing behavior in the "shock" chamber than in the "safe" chamber after only a single training trial $(F=50.307, p<0.001)$. Both the $\mathrm{rmCHI}+\operatorname{Veh}(F=133.983, p<0.001$; Fig. $5 J)$ and $\mathrm{rmCHI}+$ Met mice $(F=130.706, p<0.001$; Fig. $5 K)$ were also able to differentiate between the two contexts, albeit the difference in freezing behaviors exhibited between the "shock" and "safe" contexts were less than that seen in sham animals. When a discrimination difference score was calculated (shock freezing \% - safe freezing \%) and compared across injured groups, the metformin treated $\mathrm{rmCHI}$ animals showed a significantly improved ability to discriminate between the two contexts compared with vehicle-treated injured controls $(F=21.966, p<0.001$; Fig. $5 L$ ).

\section{Discussion}

In the present study, we examined whether metformin administered after repeated $\mathrm{mCHI}(\mathrm{rmCHI})$ alters brain tissue bioenergetics, pathology, and functional outcome. Our study revealed three key findings: (1) rmCHI increased mitochondrial proton leak in the hippocampus $2 \mathrm{~h}$ after the last injury, an effect that was reversed by postinjury administration of metformin. In addition to attenuating injury-associated proton leak, metformin also significantly enhanced ATP-linked respiration in the hippocampus; (2) while $\mathrm{rmCHI}$ did not elicit visible tissue damage or loss of hippocampal synaptic proteins, it resulted in axonal damage in the corpus callosum and hippocampal commissure. These white matter disturbances were reduced in $\mathrm{rmCHI}$ mice that received acute metformin treatment; (3) metformin administration after each head impact significantly improved motor and memory function when tested days after the termination of the drug treatment. These results support the continued evaluation of metformin as a possible concussion therapeutic, and suggest that restoration of mitochondrial function may be an effective strategy to reduce inflammation and axonal injury.

The present study used a model of $\mathrm{CHI}$ to deliver repeated impacts separated by $24 \mathrm{~h}$ to mice. This paradigm was based on previous studies which demonstrated that a single $\mathrm{mCHI}$ was insufficient to produce reliable cognitive dysfunction (DeFord et al., 2002; Meehan et al., 2012). However, when injuries were separated by a $24 \mathrm{~h}$ delay, it was found that three to five repeated injuries produced significant hippocampal-dependent learning and memory dysfunction (DeFord et al., 2002; Meehan et al., 2012; Hylin et al., 2013). Our evaluation of acute neurologic responses after each injury revealed that, although apnea and recovery of pain reflexes remained consistent across injuries, the duration of suppression of righting response decreased after the first impact (Fig. 5D). While the reason for this decrease is not clear, a few studies have suggested that brain injury can activate preconditioning pathways that may offer protection against subsequent injuries (Bolton and Saatman, 2014). For example, it has been reported that the duration of apnea and the suppression of righting responses were maximal after the first impact, but decreased following additional impacts separated by either 24 or $48 \mathrm{~h}$ (Bolton and Saatman, 2014; Bolton Hall et al., 2016). In contrast, when the injuries are separated by $72 \mathrm{~h}$, no preconditioning effects are evident on acute neurologic responses (Maynard et al., 2019). Although we did not observe any influence of postinjury metformin administration on the acute neurologic responses when the injuries were separated by $24 \mathrm{~h}$, whether its administration can stimulate preconditioning pathways in more separated injuries remains to be examined. Further, it is important to note that while metformin 
was administered after each of the four injuries, its administration can be considered preinjury for the second, third, and fourth injuries. The reported half-life of metformin varies from study-to-study, ranging from 2 to $6 \mathrm{~h}$ in mice (Kinaan et al., 2015). As metformin administration occurred $23.5 \mathrm{~h}$ before each subsequent repeat injury, it is estimated that between 4 and 12 drug half-lives would have passed by the next injury, which calculates to $>90 \%$ clearance of the drug. However, metformin signaling may persist well beyond the clearance of the drug. For example, Solskov and colleagues observed that a single dose of metformin can offer protection against coronary artery occlusion initiated $24 \mathrm{~h}$ after discontinutation of the treatment (Solskov et al., 2008). Thus, it is likely that a combination of both preinjury and postinjury effects of metformin contributed to the protection we observed.

A large body of evidence has shown that TBI increases intracellular calcium to pathologic concentrations, leading to calcium overload in mitochondria (Pandya et al., 2013; Vekaria et al., 2017). Mitochondrial calcium overload can cause proton leak, production of reactive oxygen species (ROS), and compromised oxidative phosphorylation, all of which have been observed following TBI (Griesbach et al., 2009; Pandya et al., 2009; Owens et al., 2013; Bano and Ankarcrona, 2018). Consistent with this, we observed that $\mathrm{rmCHI}$ caused a significant increase in acute proton leak within the hippocampus. This effect on proton leak was blunted in animals treated with metformin, and was associated with an increase in ATP-linked respiration. At present, it is not known how metformin exerts these protective effects, but several mechanisms are plausible (Kim et al., 2016, 2021; Chen et al., 2017; Deschemin et al., 2017; Xu et al., 2021). For example, it has been suggested that metformin may exert some of its protective effects through inhibition of mitochondrial complex 1, leading to an increase in the ADP: ATP ratio and AMPK activation (Owen et al., 2000). Although we observed that $\geq 2 \mathrm{~mm}$ metformin can inhibit complex 1 activity in isolated mitochondria, our analysis of tissue levels indicated that the brain concentration of metformin after intraperitoneal injection of $250 \mathrm{mg} / \mathrm{kg}$ (a dose previously used in a number studies and the present study) reached only 20-30 $\mu \mathrm{m}$. Although we cannot rule out the possibility of limited (spatially and/or temporally) vascular disruption that could affect metformin concentration in a local area, the bloodbrain barrier appears to remain intact after repeat mild TBI to rodents (DeFord et al., 2002; Kane et al., 2012; Meehan et al., 2012; Petraglia et al., 2014). Therefore, it is anticipated that the brain penetration of metformin is not appreciably changed as a result of the repeated injuries and is $\sim 1 / 100$ of the dose needed to inhibit complex 1 activity in vitro (please see Fig. $4 A, D$ ). These findings are consistent with other studies which have questioned the in vivo relevance of Complex I inhibition in the action of metformin (for review, see Fontaine, 2018; Pecinová et al., 2019; LaMoia and Shulman, 2021). Although controversial, conformational changes in Complex I and metformin accumulation in mitochondria (because of its charge) have been proposed as mechanisms by which Complex I inhibition may remain plausible in vivo (Owen et al., 2000; Bridges et al., 2014).
Mitochondria are dynamic organelles which balance the processes of fusion and fission to meet the energy demands of the cell. Our capillary western analyses indicated that $\mathrm{rmCHI}$ decreased the phosphorylation of Mff, while simultaneously increasing the levels of Opa1. Mff is anchored within the outer mitochondrial membrane and is a component of the mitochondrial fission complex, serving as a receptor for Drp1 (Gandre-Babbe and van der Bliek, 2008; Otera et al., 2010). Mff phosphorylation by AMPK is thought to enhance mitochondrial fission (Toyama et al., 2016). Opa1 is a GTPase expressed on the inner mitochondrial membrane whose levels and activity correlate with the extent of mitochondrial fusion (Cipolat et al., 2004). Thus, the observed decrease in Mff phosphorylation and increase in Opa1 levels we observed after rmCHI suggest a shift in the dynamic balance of mitochondria toward fusion. Interestingly, metformin restored Mff phosphorylation and increased Drp1 levels, changes that suggest increased activation of pathways that mediate mitochondrial fission. As mitochondrial fission plays an important role in the removal of damaged mitochondria by autophagy (Zhang and Lin, 2016), this may underlie the reduced proton leak and increased ATP synthesis we observed in $\mathrm{rmCHI}$ mice treated with metformin.

One of the most interesting aspects of the present study is that postinjury metformin treatment improved cognitive function. After repeated $\mathrm{CHI}$, mice displayed a significant recognition memory deficit, as well as a deficit in contextual discrimination, both processes that are dependent on the function of the hippocampus (Frankland et al., 1998; Broadbent et al., 2010; Cohen et al., 2013). These impairments were observed in the absence of overt neuronal loss or altered expression of synaptic proteins. However, we observed that $\mathrm{rmCH}$ caused white matter damage in the corpus callosum and hippocampal commissure that was accompanied by an increase in astrocyte activation. Diffusion tensor imaging (DTI) studies of concussion subjects have routinely reported damage to major white matter tracts, including the corpus callosum, with the degree of axonal injury correlating with the severity of cognitive dysfunction (Bazarian et al., 2014; Oehr and Anderson, 2017; Zhu et al., 2019). Although we cannot conclusively link the observed white matter damage and astrocyte activation to the ensuing cognitive impairments, these pathologic changes were significantly reduced in injured mice treated with metformin. A few mechanisms that may underlie traumatic axonal injury have been proposed, including activation of the calciumdependent protease calpain, decreased NAD levels, and ROS-mediated damage (Povlishock and Kontos, 1992; Kampfl et al., 1997; Büki et al., 1999; Bains and Hall, 2012; Maynard et al., 2019, 2020). As metformin has been demonstrated to inhibit calpain, activate the NAD-dependent deactylase SIRT1, and has been repeatedly shown to reduce free radical production (BonnefontRousselot et al., 2003; Yang et al., 2017; Cuyàs et al., 2018; Wang et al., 2020b), one or more of these mechanisms may contribute to the protections that we observed.

Although this is the first report to describe protective effects of metformin in a model of repeat mild TBI, it has 
been previously observed that metformin treatment was beneficial following moderate-to-severe TBI. For example, moderate-to-severe cortical impact injury in rats caused a persistent decrease in AMPK activity that was reversed by postinjury treatment with metformin. This reversal was associated with a reduction in newborn hippocampal neuron loss and an improvement in spatial memory performance (Hill et al., 2010). Using a weight drop model of brain injury, Tao et al., demonstrated that metformin reduced microglial activation and the expression of pro-inflammatory cytokines, effects attributed to inhibiting NF-KB and p38 MAPK signaling (Tao et al., 2018). A randomized clinical trial examining the safety and efficacy of metformin in severe TBI patients found that metformin treatment resulted in decreased serum levels of the astrocytic protein $\mathrm{S} 100 \mathrm{~B}$, suggesting reduced neuronal injury (Taheri et al., 2019). Taken together, these data suggest that metformin can restore mitochondrial function, reduce inflammation, offer axonal protection, and improve cognitive outcome after TBI, and supports its testing in persons at risk for repeat concussions such as athletes participating in contact sports and military personnel. As our study was conducted using only male mice, and sex-dependent effects of metformin have been reported (Park et al., 2017; Krysiak et al., 2018, 2020; Ruddy et al., 2019), additional experiments will be required to assess the influence of metformin on repeat injury in females.

\section{References}

Alimoradi N, Firouzabadi N, Fatehi R (2021) How metformin affects various malignancies by means of microRNAs: a brief review. Cancer Cell Int 21:207.

Ansari MA, Roberts KN, Scheff SW (2008) A time course of contusion-induced oxidative stress and synaptic proteins in cortex in a rat model of TBI. J Neurotrauma 25:513-526.

Bains M, Hall ED (2012) Antioxidant therapies in traumatic brain and spinal cord injury. Biochim Biophys Acta 1822:675-684.

Bano D, Ankarcrona M (2018) Beyond the critical point: an overview of excitotoxicity, calcium overload and the downstream consequences. Neurosci Lett 663:79-85.

Barkhoudarian G, Hovda DA, Giza CC (2016) The molecular pathophysiology of concussive brain injury - an update. Phys Med Rehabil Clin N Am 27:373-393.

Bazarian JJ, Zhu T, Zhong J, Janigro D, Rozen E, Roberts A, Javien H, Merchant-Borna K, Abar B, Blackman EG (2014) Persistent, long-term cerebral white matter changes after sports-related repetitive head impacts. PLoS One 9:e94734.

Ben Sahra I, Regazzetti C, Robert G, Laurent K, Le MarchandBrustel Y, Auberger P, Tanti JF, Giorgetti-Peraldi S, Bost F (2011) Metformin, independent of AMPK, induces mTOR inhibition and cell-cycle arrest through REDD1. Cancer Res 71:4366-4372.

Bennett RE, Mac Donald CL, Brody DL (2012) Diffusion tensor imaging detects axonal injury in a mouse model of repetitive closedskull traumatic brain injury. Neurosci Lett 513:160-165.

Bolton AN, Saatman KE (2014) Regional neurodegeneration and gliosis are amplified by mild traumatic brain injury repeated at 24-hour intervals. J Neuropathol Exp Neurol 73:933-947.

Bolton Hall AN, Joseph B, Brelsfoard JM, Saatman KE (2016) Repeated closed head injury in mice results in sustained motor and memory deficits and chronic cellular changes. PLoS One 11: e0159442.

Bonnefont-Rousselot D, Raji B, Walrand S, Gardès-Albert M, Jore D, Legrand A, Peynet J, Vasson MP (2003) An intracellular modulation of free radical production could contribute to the beneficial effects of metformin towards oxidative stress. Metabolism 52:586-589.

Bramlett HM, Dietrich WD (2015) Long-term consequences of traumatic brain injury: current status of potential mechanisms of injury and neurological outcomes. J Neurotrauma 32:1834-1848.

Bridges HR, Jones AJ, Pollak MN, Hirst J (2014) Effects of metformin and other biguanides on oxidative phosphorylation in mitochondria. Biochem J 462:475-487.

Broadbent NJ, Gaskin S, Squire LR, Clark RE (2010) Object recognition memory and the rodent hippocampus. Learn Mem 17:5-11.

Broussard JI, Redell JB, Zhao J, Maynard ME, Kobori N, Perez A, Hood KN, Zhang XO, Moore AN, Dash PK (2020) Mild traumatic brain injury decreases spatial information content and reduces place field stability of hippocampal CA1 neurons. J Neurotrauma 37:227-235.

Büki A, Siman R, Trojanowski JQ, Povlishock JT (1999) The role of calpain-mediated spectrin proteolysis in traumatically induced axonal injury. J Neuropathol Exp Neurol 58:365-375.

Burda JE, Bernstein AM, Sofroniew MV (2016) Astrocyte roles in traumatic brain injury. Exp Neurol 275:305-315.

Cantu D, Croker D, Shacham S, Tamir S, Dulla C (2020) In vivo KPT350 treatment decreases cortical hyperexcitability following traumatic brain injury. Brain Inj 34:1489-1496.

Capruso DX, Levin HS (1992) Cognitive impairment following closed head injury. Neurol Clin 10:879-893.

Carron SF, Sun M, Shultz SR, Rajan R (2020) Inhibitory neuronal changes following a mixed diffuse-focal model of traumatic brain injury. J Comp Neurol 528:175-198.

Chen SC, Brooks R, Houskeeper J, Bremner SK, Dunlop J, Viollet B, Logan PJ, Salt IP, Ahmed SF, Yarwood SJ (2017) Metformin suppresses adipogenesis through both AMP-activated protein kinase (AMPK)-dependent and AMPK-independent mechanisms. Mol Cell Endocrinol 440:57-68.

Choe MC, Babikian T, Difiori J, Hovda DA, Giza CC (2012) A pediatric perspective on concussion pathophysiology. Curr Opin Pediatr 24:689-695.

Cipolat S, Martins de Brito O, Dal Zilio B, Scorrano L (2004) OPA1 requires mitofusin 1 to promote mitochondrial fusion. Proc Natl Acad Sci USA 101:15927-15932.

Cohen SJ, Munchow AH, Rios LM, Zhang G, Asgeirsdóttir HN, Stackman RW Jr (2013) The rodent hippocampus is essential for nonspatial object memory. Curr Biol 23:1685-1690.

Cuyàs E, Verdura S, Llorach-Parés L, Fernández-Arroyo S, Joven J, Martin-Castillo B, Bosch-Barrera J, Brunet J, Nonell-Canals A, Sanchez-Martinez M, Menendez JA (2018) Metformin is a direct SIRT1-activating compound: computational modeling and experimental validation. Front Endocrinol (Lausanne) 9:657.

DeFord SM, Wilson MS, Rice AC, Clausen T, Rice LK, Barabnova A, Bullock R, Hamm RJ (2002) Repeated mild brain injuries result in cognitive impairment in B6C3F1 mice. J Neurotrauma 19:427438.

Deschemin JC, Foretz M, Viollet B, Vaulont S (2017) AMPK is not required for the effect of metformin on the inhibition of BMP6-induced hepcidin gene expression in hepatocytes. Sci Rep 7:12679.

Detaille D, Guigas B, Leverve X, Wiernsperger N, Devos P (2002) Obligatory role of membrane events in the regulatory effect of metformin on the respiratory chain function. Biochem Pharmacol 63:1259-1272.

Do MT, Kim HG, Khanal T, Choi JH, Kim DH, Jeong TC, Jeong HG (2013) Metformin inhibits heme oxygenase- 1 expression in cancer cells through inactivation of Raf-ERK-Nrf2 signaling and AMPK-independent pathways. Toxicol Appl Pharmacol 271:229-238.

El-Mir MY, Nogueira V, Fontaine E, Avéret N, Rigoulet M, Leverve X (2000) Dimethylbiguanide inhibits cell respiration via an indirect effect targeted on the respiratory chain complex I. J Biol Chem 275:223-228

Floyd CL, Lyeth BG (2007) Astroglia: important mediators of traumatic brain injury. Prog Brain Res 161:61-79. 
Fontaine E (2018) Metformin-induced mitochondrial complex I inhibition: facts, uncertainties, and consequences. Front Endocrinol (Lausanne) 9:753.

Frankland PW, Cestari V, Filipkowski RK, McDonald RJ, Silva AJ (1998) The dorsal hippocampus is essential for context discrimination but not for contextual conditioning. Behav Neurosci 112:863874.

Gandre-Babbe S, van der Bliek AM (2008) The novel tail-anchored membrane protein Mff controls mitochondrial and peroxisomal fission in mammalian cells. Mol Biol Cell 19:2402-2412.

Ge XH, Zhu GJ, Geng DQ, Zhang HZ, He JM, Guo AZ, Ma LL, Yu DH (2017) Metformin protects the brain against ischemia/reperfusion injury through PI3K/Akt1/JNK3 signaling pathways in rats. Physiol Behav 170:115-123.

Griesbach GS, Sutton RL, Hovda DA, Ying Z, Gomez-Pinilla F (2009) Controlled contusion injury alters molecular systems associated with cognitive performance. J Neurosci Res 87:795-805.

Gurkoff GG, Giza CC, Hovda DA (2006) Lateral fluid percussion injury in the developing rat causes an acute, mild behavioral dysfunction in the absence of significant cell death. Brain Res 1077:24-36.

Hill J, Zhao J, Dash PK (2010) High blood glucose does not adversely affect outcome in moderately brain-injured rodents. J Neurotrauma 27:1439-1448.

Hill JL, Kobori N, Zhao J, Rozas NS, Hylin MJ, Moore AN, Dash PK (2016) Traumatic brain injury decreases AMP-activated protein kinase activity and pharmacological enhancement of its activity improves cognitive outcome. J Neurochem 139:106-119.

Hsieh TH, Lee HHC, Hameed MQ, Pascual-Leone A, Hensch TK, Rotenberg A (2017) Trajectory of parvalbumin cell impairment and loss of cortical inhibition in traumatic brain injury. Cereb Cortex 27:5509-5524.

Hylin MJ, Orsi SA, Rozas NS, Hill JL, Zhao J, Redell JB, Moore AN, Dash PK (2013) Repeated mild closed head injury impairs shortterm visuospatial memory and complex learning. J Neurotrauma 30:716-726.

Inayat H, Azim MK, Baloch AA (2019) Analysis of inflammatory gene expression profile of peripheral blood leukocytes in type 2 diabetes. Immunol Invest 48:618-631.

Izzo A, Nitti M, Mollo N, Paladino S, Procaccini C, Faicchia D, Calì G, Genesio R, Bonfiglio F, Cicatiello R, Polishchuk E, Polishchuk R, Pinton P, Matarese G, Conti A, Nitsch L (2017) Metformin restores the mitochondrial network and reverses mitochondrial dysfunction in Down syndrome cells. Hum Mol Genet 26:1056-1069.

Jenkins LW, Moszynski K, Lyeth BG, Lewelt W, Dewitt DS, Allen A, Dixon CE, Povlishock JT, Majewski TJ, Clifton GL (1989) Increased vulnerability of the mildly traumatized rat brain to cerebral ischemia: the use of controlled secondary ischemia as a research tool to identify common or different mechanisms contributing to mechanical and ischemic brain injury. Brain Res 477:211-224.

Jin J, Gu H, Anders NM, Ren T, Jiang M, Tao M, Peng Q, Rudek MA, Duan W (2016) Metformin protects cells from mutant Huntingtin toxicity through activation of AMPK and modulation of mitochondrial dynamics. Neuromolecular Med 18:581-592.

Kalender A, Selvaraj A, Kim SY, Gulati P, BrÃlé S, Viollet B, Kemp BE, Bardeesy N, Dennis P, Schlager JJ, Marette A, Kozma SC, Thomas G (2010) Metformin, independent of AMPK, inhibits mTORC1 in a rag GTPase-dependent manner. Cell Metab 11:390401.

Kampfl A, Posmantur RM, Zhao X, Schmutzhard E, Clifton GL, Hayes RL (1997) Mechanisms of calpain proteolysis following traumatic brain injury: implications for pathology and therapy: implications for pathology and therapy: a review and update. J Neurotrauma 14:121-134.

Kane MJ, Angoa-Pérez M, Briggs DI, Viano DC, Kreipke CW, Kuhn DM (2012) A mouse model of human repetitive mild traumatic brain injury. J Neurosci Methods 203:41-49.

Kaneto H, Kimura T, Obata A, Shimoda M, Kaku K (2021) Multifaceted mechanisms of action of metformin which have been unraveled one after another in the long history. Int $\mathrm{J}$ Mol Sci 22:2596.
Kanigur Sultuybek G, Soydas T, Yenmis G (2019) NF- $\kappa$ B as the mediator of metformin's effect on ageing and ageing-related diseases. Clin Exp Pharmacol Physiol 46:413-422.

Karise I, Bargut TC, Del Sol M, Aguila MB, Mandarim-de-Lacerda CA (2019) Metformin enhances mitochondrial biogenesis and thermogenesis in brown adipocytes of mice. Biomed Pharmacother 111:1156-1165.

Kim EK, Lee SH, Jhun JY, Byun JK, Jeong JH, Lee SY, Kim JK, Choi JY, Cho ML (2016) Metformin prevents fatty liver and improves balance of white/brown adipose in an obesity mouse model by inducing FGF21. Mediators Inflamm 2016:5813030.

Kim TS, Lee M, Park M, Kim SY, Shim MS, Lee CY, Choi DH, Cho Y (2021) Metformin and dichloroacetate suppress proliferation of liver cancer cells by inhibiting mTOR complex 1 . Int $\mathrm{J}$ Mol Sci 22:10027.

Kinaan M, Ding H, Triggle CR (2015) Metformin: an old drug for the treatment of diabetes but a new drug for the protection of the endothelium. Med Princ Pract 24:401-415.

Krysiak R, Szkróbka W, Okopień B (2018) Sex-dependent effect of metformin on serum prolactin levels in hyperprolactinemic patients with type 2 diabetes: a pilot study. Exp Clin Endocrinol Diabetes 126:342-348.

Krysiak R, Szkróbka W, Okopień B (2020) The impact of testosterone on metformin action on hypothalamic-pituitary-thyroid axis activity in men: a pilot study. J Clin Pharmacol 60:164-171.

Kukidome D, Nishikawa T, Sonoda K, Imoto K, Fujisawa K, Yano M, Motoshima H, Taguchi T, Matsumura T, Araki E (2006) Activation of AMP-activated protein kinase reduces hyperglycemia-induced mitochondrial reactive oxygen species production and promotes mitochondrial biogenesis in human umbilical vein endothelial cells. Diabetes 55:120-127.

Łabuzek K, Suchy D, Gabryel B, Bielecka A, Liber S, Okopień B (2010) Quantification of metformin by the HPLC method in brain regions, cerebrospinal fluid and plasma of rats treated with lipopolysaccharide. Pharmacol Rep 62:956-965.

LaMoia TE, Shulman GI (2021) Cellular and molecular mechanisms of metformin action. Endocr Rev 42:77-96.

Lengyel E, Litchfield LM, Mitra AK, Nieman KM, Mukherjee A, Zhang Y, Johnson A, Bradaric M, Lee W, Romero IL (2015) Metformin inhibits ovarian cancer growth and increases sensitivity to paclitaxel in mouse models. Am J Obstet Gynecol 212:479.e1-479.e10.

Li W, Chaudhari K, Shetty R, Winters A, Gao X, Hu Z, Ge WP, Sumien N, Forster M, Liu R, Yang SH (2019) Metformin alters locomotor and cognitive function and brain metabolism in normoglycemic mice. Aging Dis 10:949-963.

Lyeth BG, Jenkins LW, Hamm RJ, Dixon CE, Phillips LL, Clifton GL, Young HF, Hayes RL (1990) Prolonged memory impairment in the absence of hippocampal cell death following traumatic brain injury in the rat. Brain Res 526:249-258.

Margulies S, Anderson G, Atif F, Badaut J, Clark R, Empey P, Guseva M, Hoane M, Huh J, Pauly J, Raghupathi R, Scheff S, Stein D, Tang H, Hicks M (2016) Combination therapies for traumatic brain injury: retrospective considerations. J Neurotrauma 33:101-112.

Marmarou CR, Walker SA, Davis CL, Povlishock JT (2005) Quantitative analysis of the relationship between intra-axonal neurofilament compaction and impaired axonal transport following diffuse traumatic brain injury. J Neurotrauma 22:1066-1080.

Matsuzaki S, Humphries KM (2015) Selective inhibition of deactivated mitochondrial complex I by biguanides. Biochemistry 54:2011-2021.

Maynard ME, Underwood EL, Redell JB, Zhao J, Kobori N, Hood KN, Moore AN, Dash PK (2019) Carnosic Acid improves outcome after repetitive mild traumatic brain injury. J Neurotrauma 36:21472152.

Maynard ME, Redell JB, Zhao J, Hood KN, Vita SM, Kobori N, Dash PK (2020) Sarm1 loss reduces axonal damage and improves cognitive outcome after repetitive mild closed head injury. Exp Neurol 327:113207. 
McCauley SR, Wilde EA, Barnes A, Hanten G, Hunter JV, Levin HS, Smith DH (2014) Patterns of early emotional and neuropsychological sequelae after mild traumatic brain injury. J Neurotrauma 31:914-925.

Meconi A, Wortman RC, Wright DK, Neale KJ, Clarkson M, Shultz SR, Christie BR (2018) Repeated mild traumatic brain injury can cause acute neurologic impairment without overt structural damage in juvenile rats. PLoS One 13:e0197187.

Meehan WP 3rd, Zhang J, Mannix R, Whalen MJ (2012) Increasing recovery time between injuries improves cognitive outcome after repetitive mild concussive brain injuries in mice. Neurosurgery 71:885-891.

Mouzon BC, Chaytow H, Crynen G, Bachmeier C, Stewart JE, Mullan M, Stewart W, Crawford FC (2012) Repetitive mild traumatic brain injury in a mouse model produces learning and memory deficits accompanied by histological changes. J Neurotrauma 29:2761-2773.

Nair AB, Jacob S (2016) A simple practice guide for dose conversion between animals and human. J Basic Clin Pharm 7:27-31.

Oehr L, Anderson J (2017) Diffusion-tensor imaging findings and cognitive function following hospitalized mixed-mechanism mild traumatic brain injury: a systematic review and meta-analysis. Arch Phys Med Rehabil 98:2308-2319.

Oliveira WH, Nunes AK, França ME, Santos LA, Lós DB, Rocha SW, Barbosa KP, Rodrigues GB, Peixoto CA (2016) Effects of metformin on inflammation and short-term memory in streptozotocin-induced diabetic mice. Brain Res 1644:149-160.

Otera H, Wang C, Cleland MM, Setoguchi K, Yokota S, Youle RJ, Mihara K (2010) Mff is an essential factor for mitochondrial recruitment of Drp1 during mitochondrial fission in mammalian cells. J Cell Biol 191:1141-1158.

Ou Z, Kong X, Sun X, He X, Zhang L, Gong Z, Huang J, Xu B, Long D, Li J, Li Q, Xu L, Xuan A (2018) Metformin treatment prevents amyloid plaque deposition and memory impairment in APP/PS1 mice. Brain Behav Immun 69:351-363.

Owen MR, Doran E, Halestrap AP (2000) Evidence that metformin exerts its anti-diabetic effects through inhibition of complex 1 of the mitochondrial respiratory chain. Biochem J 348:607-614.

Owens K, Park JH, Schuh R, Kristian T (2013) Mitochondrial dysfunction and $\mathrm{NAD}(+)$ metabolism alterations in the pathophysiology of acute brain injury. TransI Stroke Res 4:618-634.

Palacios EM, Owen JP, Yuh EL, Wang MB, Vassar MJ, Ferguson AR, Diaz-Arrastia R, Giacino JT, Okonkwo DO, Robertson CS, Stein MB, Temkin N, Jain S, McCrea M, MacDonald CL, Levin HS, Manley GT, Mukherjee P; TRACK-TBI Investigators (2020) The evolution of white matter microstructural changes after mild traumatic brain injury: a longitudinal DTI and NODDI study. Sci Adv 6: eaaz6892.

Pandya JD, Pauly JR, Sullivan PG (2009) The optimal dosage and window of opportunity to maintain mitochondrial homeostasis following traumatic brain injury using the uncoupler FCCP. Exp Neurol 218:381-389.

Pandya JD, Nukala VN, Sullivan PG (2013) Concentration dependent effect of calcium on brain mitochondrial bioenergetics and oxidative stress parameters. Front Neuroenergetics 5:10.

Park JW, Lee JH, Park YH, Park SJ, Cheon JH, Kim WH, Kim TI (2017) Sex-dependent difference in the effect of metformin on colorectal cancer-specific mortality of diabetic colorectal cancer patients. World J Gastroenterol 23:5196-5205.

Pecinová A, Brázdová A, Drahota Z, Houštěk J, Mráček T (2019) Mitochondrial targets of metformin-Are they physiologically relevant? Biofactors 45:703-711.

Petraglia AL, Plog BA, Dayawansa S, Dashnaw ML, Czerniecka K, Walker CT, Chen M, Hyrien O, lliff JJ, Deane R, Huang JH, Nedergaard M (2014) The pathophysiology underlying repetitive mild traumatic brain injury in a novel mouse model of chronic traumatic encephalopathy. Surg Neurol Int 5:184.

Pintana H, Apaijai N, Pratchayasakul W, Chattipakorn N, Chattipakorn SC (2012) Effects of metformin on learning and memory behaviors and brain mitochondrial functions in high fat diet induced insulin resistant rats. Life Sci 91:409-414.

Potter WB, O'Riordan KJ, Barnett D, Osting SM, Wagoner M, Burger C, Roopra A (2010) Metabolic regulation of neuronal plasticity by the energy sensor AMPK. PLoS One 5:e8996.

Povlishock JT, Kontos HA (1992) The role of oxygen radicals in the pathobiology of traumatic brain injury. Hum Cell 5:345-353.

Rahimi S, Ferdowsi A, Siahposht-Khachaki A (2020) Neuroprotective effects of metformin on traumatic brain injury in rats is associated with the AMP-activated protein kinase signaling pathway. Metab Brain Dis 35:1135-1144.

Ruddy RM, Adams KV, Morshead CM (2019) Age- and sex-dependent effects of metformin on neural precursor cells and cognitive recovery in a model of neonatal stroke. Sci Adv 5:eaax1912.

Saatman KE, Duhaime AC, Bullock R, Maas Al, Valadka A, Manley GT; Workshop Scientific Team and Advisory Panel Members (2008) Classification of traumatic brain injury for targeted therapies. J Neurotrauma 25:719-738.

Sekine Y, Zyryanova A, Crespillo-Casado A, Fischer PM, Harding HP, Ron D (2015) Stress responses. Mutations in a translation initiation factor identify the target of a memory-enhancing compound. Science 348:1027-1030.

Sen T, Gupta R, Kaiser H, Sen N (2017) Activation of PERK elicits memory impairment through inactivation of CREB and downregulation of PSD95 after traumatic brain injury. J Neurosci 37:59005911.

Shenton ME, Hamoda HM, Schneiderman JS, Bouix S, Pasternak O, Rathi Y, Vu MA, Purohit MP, Helmer K, Koerte I, Lin AP, Westin CF, Kikinis R, Kubicki M, Stern RA, Zafonte R (2012) A review of magnetic resonance imaging and diffusion tensor imaging findings in mild traumatic brain injury. Brain Imaging Behav 6:137-192.

Sims NR, Anderson MF (2008) Isolation of mitochondria from rat brain using Percoll density gradient centrifugation. Nat Protoc 3:1228-1239.

Solskov L, Løfgren B, Kristiansen SB, Jessen N, Pold R, Nielsen TT, Bøtker HE, Schmitz O, Lund S (2008) Metformin induces cardioprotection against ischaemia/reperfusion injury in the rat heart 24 hours after administration. Basic Clin Pharmacol Toxicol 103:8287.

Stone JR, Okonkwo DO, Dialo AO, Rubin DG, Mutlu LK, Povlishock JT, Helm GA (2004) Impaired axonal transport and altered axolemmal permeability occur in distinct populations of damaged axons following traumatic brain injury. Exp Neurol 190:59-69.

Taheri A, Emami M, Asadipour E, Kasirzadeh S, Rouini MR, Najafi A, Heshmat R, Abdollahi M, Mojtahedzadeh M (2019) A randomized controlled trial on the efficacy, safety, and pharmacokinetics of metformin in severe traumatic brain injury. J Neurol 266:19881997.

Tang G, Yang H, Chen J, Shi M, Ge L, Ge X, Zhu G (2017) Metformin ameliorates sepsis-induced brain injury by inhibiting apoptosis, oxidative stress and neuroinflammation via the PI3K/Akt signaling pathway. Oncotarget 8:97977-97989.

Tao L, Li D, Liu H, Jiang F, Xu Y, Cao Y, Gao R, Chen G (2018) Neuroprotective effects of metformin on traumatic brain injury in rats associated with NF- $\kappa \mathrm{B}$ and MAPK signaling pathway. Brain Res Bull 140:154-161.

Tehranian R, Rose ME, Vagni V, Pickrell AM, Griffith RP, Liu H, Clark RS, Dixon CE, Kochanek PM, Graham SH (2008) Disruption of Bax protein prevents neuronal cell death but produces cognitive impairment in mice following traumatic brain injury. J Neurotrauma 25:755-767.

Thinnes A, Westenberger M, Piechotta C, Lehto A, Wirth F, Lau H, Klein J (2021) Cholinergic and metabolic effects of metformin in mouse brain. Brain Res Bull 170:211-217.

Toyama EQ, Herzig S, Courchet J, Lewis TL Jr, Losón OC, Hellberg K, Young NP, Chen H, Polleux F, Chan DC, Shaw RJ (2016) Metabolism. AMP-activated protein kinase mediates mitochondrial fission in response to energy stress. Science 351:275-281.

Tucker LB, Winston BS, Liu J, Velosky AG, Fu AH, Grillakis AA, McCabe JT (2019) Sex differences in cued fear responses and 
parvalbumin cell density in the hippocampus following repetitive concussive brain injuries in C57BL/6J mice. PLoS One 14: e0222153.

Varma MR, Dixon CE, Jackson EK, Peters GW, Melick JA, Griffith RP, Vagni VA, Clark RS, Jenkins LW, Kochanek PM (2002) Administration of adenosine receptor agonists or antagonists after controlled cortical impact in mice: effects on function and histopathology. Brain Res 951:191-201.

Vekaria HJ, Talley Watts L, Lin AL, Sullivan PG (2017) Targeting mitochondrial dysfunction in CNS injury using Methylene Blue; still a magic bullet? Neurochem Int 109:117-125.

Viollet B, Guigas B, Sanz Garcia N, Leclerc J, Foretz M, Andreelli F (2012) Cellular and molecular mechanisms of metformin: an overview. Clin Sci (Lond) 122:253-270.

Wang S, Lin Y, Xiong X, Wang L, Guo Y, Chen Y, Chen S, Wang G, Lin P, Chen H, Yeung SJ, Bremer E, Zhang H (2020a) Low-dose metformin reprograms the tumor immune microenvironment in human esophageal cancer: results of a phase II clinical trial. Clin Cancer Res 26:4921-4932.

Wang Y, Zhao J, Guo FL, Gao X, Xie X, Liu S, Yang X, Yang X, Zhang L, Ye Y, Fan L, Wang J (2020b) Metformin ameliorates synaptic defects in a mouse model of AD by inhibiting Cdk5 activity. Front Cell Neurosci 14:170.

Wang Y, An H, Liu T, Qin C, Sesaki H, Guo S, Radovick S, Hussain M, Maheshwari A, Wondisford FE, O'Rourke B, He L (2019) Metformin improves mitochondrial respiratory activity through activation of AMPK. Cell Rep 29:1511-1523.e5.
Wheaton WW, Weinberg SE, Hamanaka RB, Soberanes S, Sullivan LB, Anso E, Glasauer A, Dufour E, Mutlu GM, Budigner GS, Chandel NS (2014) Metformin inhibits mitochondrial complex I of cancer cells to reduce tumorigenesis. Elife 3:e02242.

Wu H, Esteve E, Tremaroli V, Khan MT, Caesar R, Mannerås-Holm L, Ståhlman $M$, Olsson LM, Serino $M$, Planas-Fèlix $M$, Xifra $G$, Mercader JM, Torrents D, Burcelin R, Ricart W, Perkins R, Fernàndez-Real JM, Bäckhed F (2017) Metformin alters the gut microbiome of individuals with treatment-naive type 2 diabetes, contributing to the therapeutic effects of the drug. Nat Med 23:850858.

Xu X, Sun Y, Cen X, Shan B, Zhao Q, Xie T, Wang Z, Hou T, Xue Y, Zhang M, Peng D, Sun Q, Yi C, Najafov A, Xia H (2021) Metformin activates chaperone-mediated autophagy and improves disease pathologies in an Alzheimer disease mouse model. Protein Cell 12:769-787.

Yang H, Gu ZT, Li L, Maegele M, Zhou BY, Li F, Zhao M, Zhao KS (2017) SIRT1 plays a neuroprotective role in traumatic brain injury in rats via inhibiting the p38 MAPK pathway. Acta Pharmacol Sin 38:168-181.

Zhang CS, Lin SC (2016) AMPK promotes autophagy by facilitating mitochondrial fission. Cell Metab 23:399-401.

Zhu J, Ling J, Ding N (2019) Association between diffusion tensor imaging findings and cognitive outcomes following mild traumatic brain injury: a PRISMA-compliant meta-analysis. ACS Chem Neurosci 10:4864-4869. 